\title{
Article \\ The Influence of Anisotropic Surface Reflection on Earth's Outgoing Shortwave Radiance in the Lunar Direction
}

\author{
Jie Wu ${ }^{1,2}$, Huadong Guo ${ }^{1,2}$, Yixing Ding ${ }^{1, *}$, Haolu Shang ${ }^{1}$, Tong $\mathrm{Li}^{3}$, Lei $\mathrm{Li}^{3}$ and Mingyang $\mathrm{Lv}^{1}$ \\ 1 Key Laboratory of Digital Earth Science, Aerospace Information Research Institute, Chinese Academy of \\ Sciences, Beijing 100094, China; wujie2017@radi.ac.cn (J.W.); hdguo@radi.ac.cn (H.G.); \\ shanghl@radi.ac.cn (H.S.); lvmy@aircas.ac.cn (M.L.) \\ 2 College of Resources and Environment, University of Chinese Academy of Sciences, Beijing 100049, China \\ 3 Beijing Institute of Electronic System Engineering, Beijing 100039, China; litongcas@aircas.ac.cn (T.L.); \\ lilei@aircas.ac.cn (L.L.) \\ * Correspondence: dingyx@radi.ac.cn
}

check for updates

Citation: Wu, J.; Guo, H.; Ding, Y.; Shang, H.; Li, T.; Li, L.; Lv, M. The Influence of Anisotropic Surface Reflection on Earth's Outgoing Shortwave Radiance in the Lunar Direction. Remote Sens. 2022, 14, 887. https://doi.org/10.3390/rs14040887

Academic Editor: Steven Dewitte

Received: 25 January 2022

Accepted: 10 February 2022

Published: 12 February 2022

Publisher's Note: MDPI stays neutral with regard to jurisdictional claims in published maps and institutional affiliations.

Copyright: (c) 2022 by the authors. Licensee MDPI, Basel, Switzerland. This article is an open access article distributed under the terms and conditions of the Creative Commons Attribution (CC BY) license (https:// creativecommons.org/licenses/by/ $4.0 /)$.

\begin{abstract}
The variation in the radiation budget at Earth's top of the atmosphere (TOA) represents the most fundamental metric defining the status of global climate change. The accurate estimation of Earth's shortwave radiant exitance is of critical importance to study Earth's radiation budget (ERB) at TOA. Measuring Earth's outgoing shortwave radiance (OSR) is a key point to estimate Earth's shortwave radiant exitance. Compared with space-borne satellite systems, Moon-based sensors (MS) could provide large-scale, continuous, and long-term data for Earth radiation observations, bringing a new perspective on ERB. However, the factors affecting the estimation of Earth's OSR in the lunar direction have not yet been fully explored, for example, anisotropic surface reflection and the effects of clouds and aerosols on radiation budget. In this work, we only focused on the influence of anisotropic surface reflection. To evaluate the extent of this influence, we constructed a model to estimate Earth's OSR in the lunar direction (EOSRiLD), integrating the variables of anisotropic surface reflection (scene types, solar zenith angles, viewing zenith angles, and relative azimuth angles) and radiant flux in Moon-viewed sunlit regions. Then, we discussed it over three time periods (Earth's rotation, revolution period, and synodic month cycle) and analyzed the impact of three variables (area of the Moon-viewed sunlit region, scene types, and incident-viewing angular bins) on anisotropic EOSRiLD. Our results indicate that EOSRiLD based on the assumptions of anisotropic and isotropic reflection is different but they all show the same monthly cycle change, which is related to the area of the Moon-viewed sunlit region. At the beginning and end of the lunar month, the differences between anisotropy and isotropy are greatest in each cycle; when it is close to the first half of each cycle, there is a small difference peak. Both anisotropy and isotropy are caused by the relative azimuth angles between the Sun and Moon. In conclusion, even if the Moon-based platform has a wider scope than space-borne satellites, the difference is still large between anisotropy and isotropy. Therefore, we still need to consider the anisotropic surface reflection based on the Moon-based observation.
\end{abstract}

Keywords: Earth's radiation budget; Moon-based observation; outgoing shortwave radiance; anisotropic surface reflection

\section{Introduction}

Frequent occurrences of extreme climate events in recent years have attracted increasing attention to global climate change among scientists. The variation in the radiation budget at the TOA (top of the atmosphere) represents the most fundamental metric defining the status of global climate change [1]. A positive budget balance reflects an energy accumulation in the Earth system, while a negative budget balance indicates a release. In the long-term balance, about $30 \%$ of the incoming solar shortwave radiation is directly reflected and scattered by Earth's atmosphere, ocean, and land surface. The remainder is converted into different forms, stored in the Earth system, and will eventually be released in the 
form of outgoing longwave radiation [1-3]. Generally, if the incoming shortwave radiation equals the outgoing radiation (the reflected shortwave radiation and emitted longwave radiation) during a period, the Earth system is in an energy-balanced status. Therefore, the key point to measure or estimate Earth's radiation budget is the absolute determination of incoming radiation and outgoing radiation at TOA. Due to the stability of Earth's orbit, measuring incoming radiation at Earth's TOA is much more reliable than the estimation of outgoing radiation. Specifically, the estimation of total shortwave outgoing radiation is affected by significant uncertainties as a result of the complex anisotropic reflecting and scattering processes in the Earth system [4]. Therefore, the accurate estimation of the OSR (outgoing shortwave radiance) is of critical importance to improve the estimation of the ERB (Earth's radiation budget) at TOA.

There have been several approaches that can be used to estimate ERB. The first depends on satellite instruments that measure the incoming solar radiation, the reflected solar radiation, and the emitted thermal radiation [5-7]. Since the 1980s, American and European scientists have carried out various satellite observation programs, such as the Earth Radiation Budget Experiment [8,9] (ERBE, 1984-1994), the Clouds and Earth's Radiant Energy System [10] (CERES, 1997-present), and the Solar Radiation and Climate Experiment [11] (SORCE, 2003-present). These low-Earth orbit (LEO) satellites play an important role in research on the global radiant energy balance. However, due to limited temporal sampling, they do not allow for monitoring variations at small time scales, for example, changes in cloud fraction and aerosols, which are crucial parameters to estimate ERB accurately [12,13]. The Geostationary Earth Radiation Budget (GERB) instrument provided the first dedicated observation of ERB from a geostationary orbit, along with cloud effects at each observed location $[14,15]$. However, only when three geostationary satellites are evenly placed in orbit can we reach global coverage. The National Institute of Standards and Technology Advanced Radiometer (NISTAR) on the Deep Space Climate Observatory (DSCOVR) is a cavity radiometer designed to measure the absolute, spectrally integrated irradiance reflected and emitted from the entire sunlit face of Earth from L1 orbit, which is the neutral gravity point between Earth and the Sun (approximately one million miles from Earth). It not only provides a unique angular perspective but can also be used as a complement to other ERB observation systems [16]. Another estimation approach depends on the estimation of the total change in energy stored in the climate system $[17,18]$. One typical step in this approach is to estimate the change in ocean heat capacity (OHC) [19], which is obtained from the difference in the measured temperature and climatology along a vertical profile in the ocean. It is mainly implemented using the Argo array of autonomous profiling floats. However, due to the coverage limitation of the floats, errors in this approach are too large to provide robust estimates of the deep ocean contribution [20,21]. Earthshine observation is a ground-based method to estimate the planetary albedo of Earth [22-24]. The nearside of the Moon facing Earth can be divided into the sunlit part and the dark part. The brightness of the sunlit part is attributed to direct sunlight, while the brightness of the dark part hinges on the sunlight reflected by Earth. Earth's albedo in a particular Earth phase can be acquired by comparing the radiation intensity of the sunlit part and the dark part. Although this method is not accurate, it proves the feasibility and potentiality to observe Earth's radiation balance on the Moon.

Due to the limitations of the existing methods, it is necessary to establish new methods that can provide large-scale, continuous and long-term data for ERB observations. In this paper, the Moon is introduced as a new ERB observation platform. The Moon is the only natural satellite of Earth. Many countries have implemented a lunar exploration program with increasing interest in Moon exploration, and various experts have focused on the Moon [25-32]. Compared with artificial satellite platforms, the Moon has several advantages. The Moon is more stable, which increases the possibility for instruments deployed on the Moon to provide consistent, long-term sequences of observations. The average distance between the Moon and Earth is $380,000 \mathrm{~km}$, which is about 60 times the radius of Earth. Therefore, the instruments installed on the near side of the Moon can 
observe Earth as a point source of anisotropic radiation. Compared with the limited field of view of satellite-based observatories [33], we can obtain an overall understanding of ERB at a hemisphere scope using a Moon-based platform. Furthermore, it is possible to obtain independent observations on the overall trend of global climate change and bring a new perspective on ERB.

To take Earth as a source of anisotropic radiation, the distribution of scene type and the anisotropy of each type should be considered. In previous work, the former has been modeled utilizing land cover data [34], and the latter has been modeled by angular distribution models, proposed by the ERBE and CERES teams [35]. The reflection of the Earth's surface shows strong anisotropy, especially in the shortwave bands $(0.3-5 \mu \mathrm{m})[35,36]$. If we regard the surface reflection as isotropic, it will lead to more uncertainties in the estimation. The Moon-based platform is much higher than LEO satellites; therefore, only a small field-of-view (about $2^{\circ}$ ) is needed to observe the near-half-globe scope on the Moon-based platform. In this paper, our aim is to explore whether the difference is still large between anisotropy and isotropy from the Moon-based platform. We constructed a model to simulate Earth's OSR in the lunar direction (EOSRiLD, the global mean shortwave radiance in the lunar direction from all Moon-viewed sunlit regions) and discussed it over three different time scales. The primary method of our study is to integrate the variables of anisotropic surface reflection (scene types, solar zenith angles, viewing zenith angles, and relative azimuth angles) and radiant flux in Moon-viewed sunlit regions. The second part presents the model, the construction process, and the utilized data. In Section 3, the changes in the EOSRiLD based on the anisotropy and isotropy over three time periods are discussed. Then, the impact of the area of the Moon-viewed sunlit region and anisotropic factors on the EOSRiLD are analyzed. Our conclusions are presented in Section 5.

\section{Methods}

The goal of this study is to evaluate the influence of anisotropic surface reflection on the EOSRiLD. It is a key step to simulate the EOSRiLD, which requires two main data: the Moonviewed sunlit region and Earth's outgoing radiation in the lunar direction. The former follows step one in Figure 1, to obtain the Sun-Earth-Moon observation geometry and angle parameters of the observational scope. The latter follows step two in Figure 1, integrating the variables of anisotropic surface reflection and radiant flux in the observational scope.
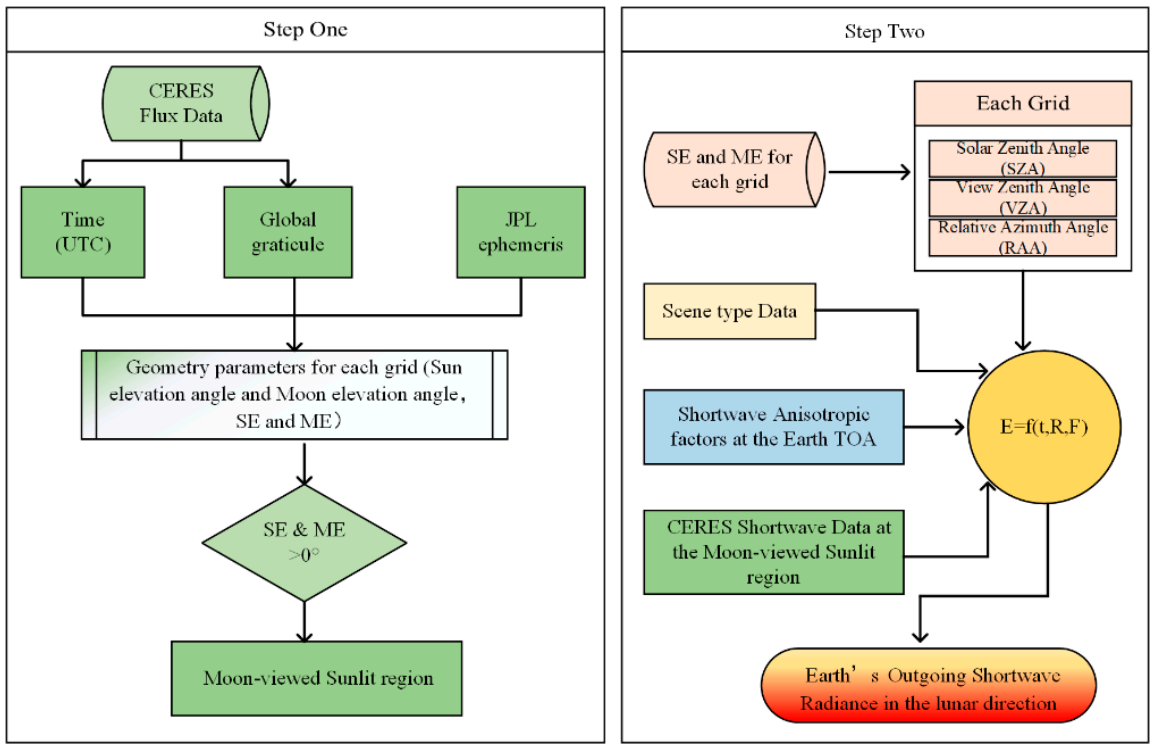

Figure 1. Flowchart of the model established for deriving Earth's outgoing shortwave radiance in the lunar direction. 


\subsection{Spatiotemporal Distribution of the Moon-Viewed Sunlit Region}

Because the orbital relationship between the Sun, Moon, and Earth is different from the LEO satellites and Earth, we need to build a new geometric observation relationship to simulate the Moon-viewed sunlit region (MsR). As Figure 2 shows, sunlight hits Earth's TOA almost parallelly, and the sunlit portion is a hemisphere region; the region of Earth facing the Moon is also nearly a hemisphere. The intersection of these two hemispheres is the sunlit portion of the Moon-viewed region.

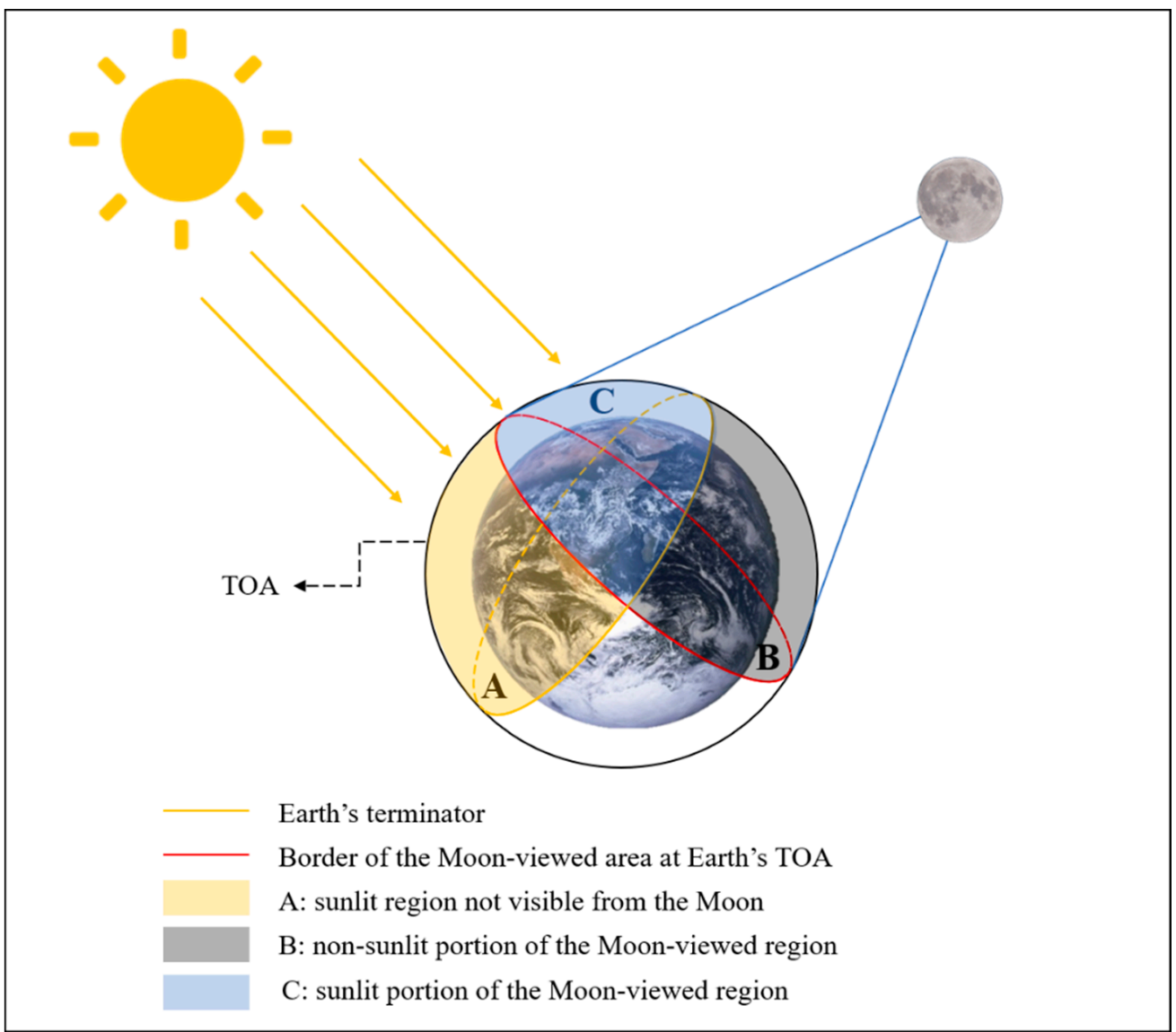

Figure 2. Illustration of the sunlit portions of the Moon-viewed region.

Related to the MsR, there are three important vectors all starting from the center of Earth: the vector pointing to the sensor on the Moon, the vector pointing to the Sun, and the vector pointing to the origin of the geographic coordinates. The first two jointly define the contour of the visible area of Moon-based sensors, and the last indicates the visible part of Earth from the Moon. The three vectors all vary in time, and thus the instantaneous MsR will change quickly with time. To obtain the spatiotemporal distribution of MsR, the Sun, Moon, and Earth should be unified under the same coordinate system. The main work of this study, illustrated by the flowchart in Figure 3, was carried out around the reference system conversion. 


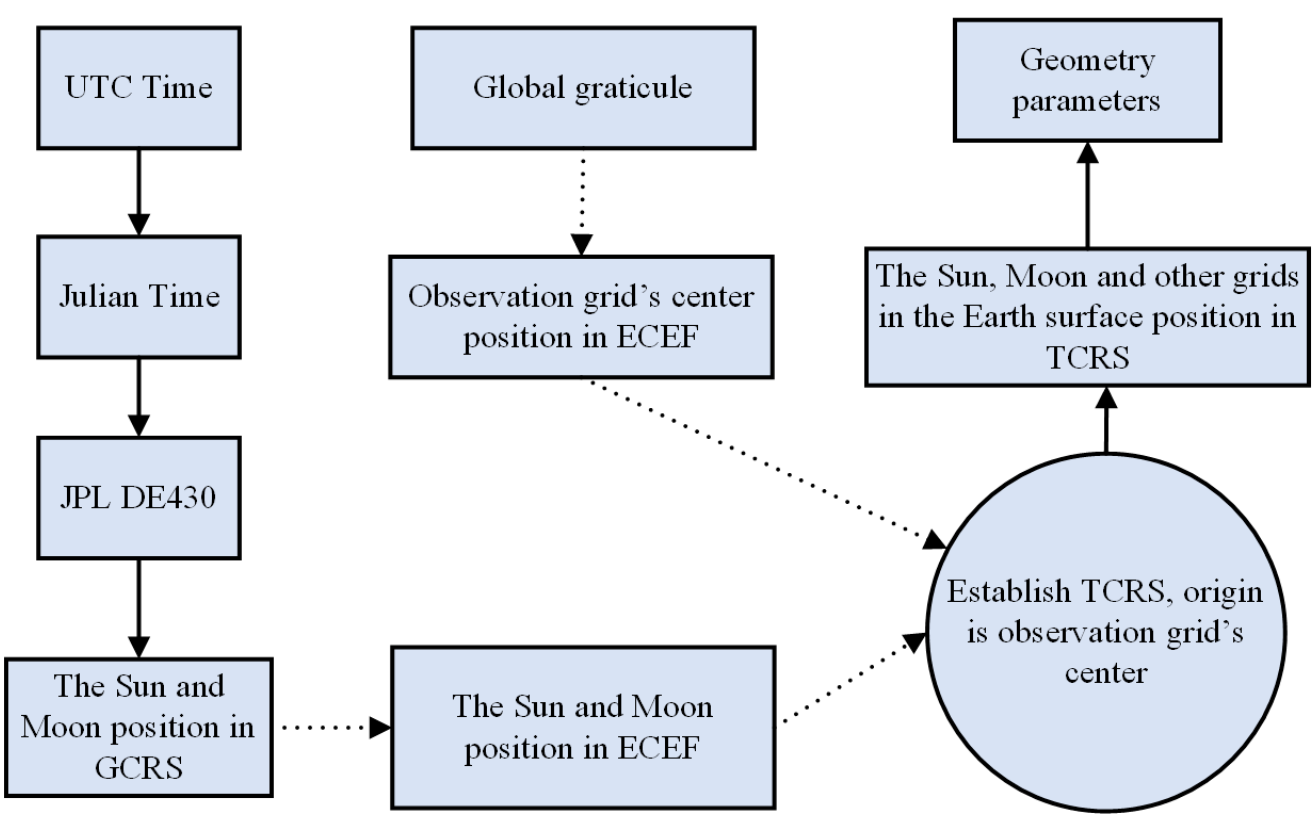

Figure 3. Transformation of reference systems to obtain geometrical parameters.

\subsubsection{The Moon-Viewed Sunlit Region on Earth}

In the Moon-viewed sunlit region, the Sun and the Moon are both visible. Therefore, a criterion can be that if a grid is in the Moon-viewed sunlit area, the Moon elevation angle and Sun elevation angle of the grid should both be greater than $0^{\circ}$. According to the criterion, the Moon-viewed sunlit region can be obtained.

\subsubsection{Transformation of the Reference Systems}

The Moon and Sun elevation angles must be calculated in the Topocentric Cartesian Reference System (TCRS). However, the Sun and Moon positions are given by JPL (Jet Propulsion Laboratory) ephemeris in the geocentric celestial reference system (GCRS). Thus, the coordinates need to be transformed. Three coordinate systems are considered in the coordinate transformation, as shown in Figure 4.

The geocentric celestial reference system (GCRS) is a geocentric coordinate that does not rotate with Earth (red line in Figure 4). Its origin is the mass center of Earth. The X-Y plane coincides with the equatorial plane of Earth. The $X$-axis points to the vernal equinox; the $Z$-axis is perpendicular to the equatorial plane and points to the North Pole, and the $Y$-axis is determined according to the right-hand rule [37].

The geodetic coordinate system (GCS) is a coordinate system established with a reference ellipsoid as the datum. Its origin is the mass center of Earth. It is expressed by three elements of geodetic longitude, geodetic latitude, and geodetic altitude. However, for the sake of simplicity, we only consider the longitude and latitude in this paper.

The Earth-centered Earth-fixed (ECEF) coordinate system is a geocentric coordinate that rotates with Earth (yellow line in Figure 4). Its origin is also the mass center of Earth. The $X$-axis points to the intersection of the prime meridian and equator, the $Z$-axis points to Earth's North Pole, and the $Y$-axis is also determined according to the right-hand rule [37].

The topocentric Cartesian reference system (TCRS) is aligned with the local horizontal plane, which means the plane is tangent to the Earth surfaces at the observer's local point (green line in Figure 4). The observer's local point is the origin of TCRS, the $X$-axis points to the east and in parallel with the local latitude line, the $Y$-axis points to the north celestial pole in the direction of the local meridian, and the $Z$-axis is determined according to the right-hand rule and points to the zenith as the positive [38].

Detailed descriptions of the transformation of these coordinate systems can be found in Appendix B. 


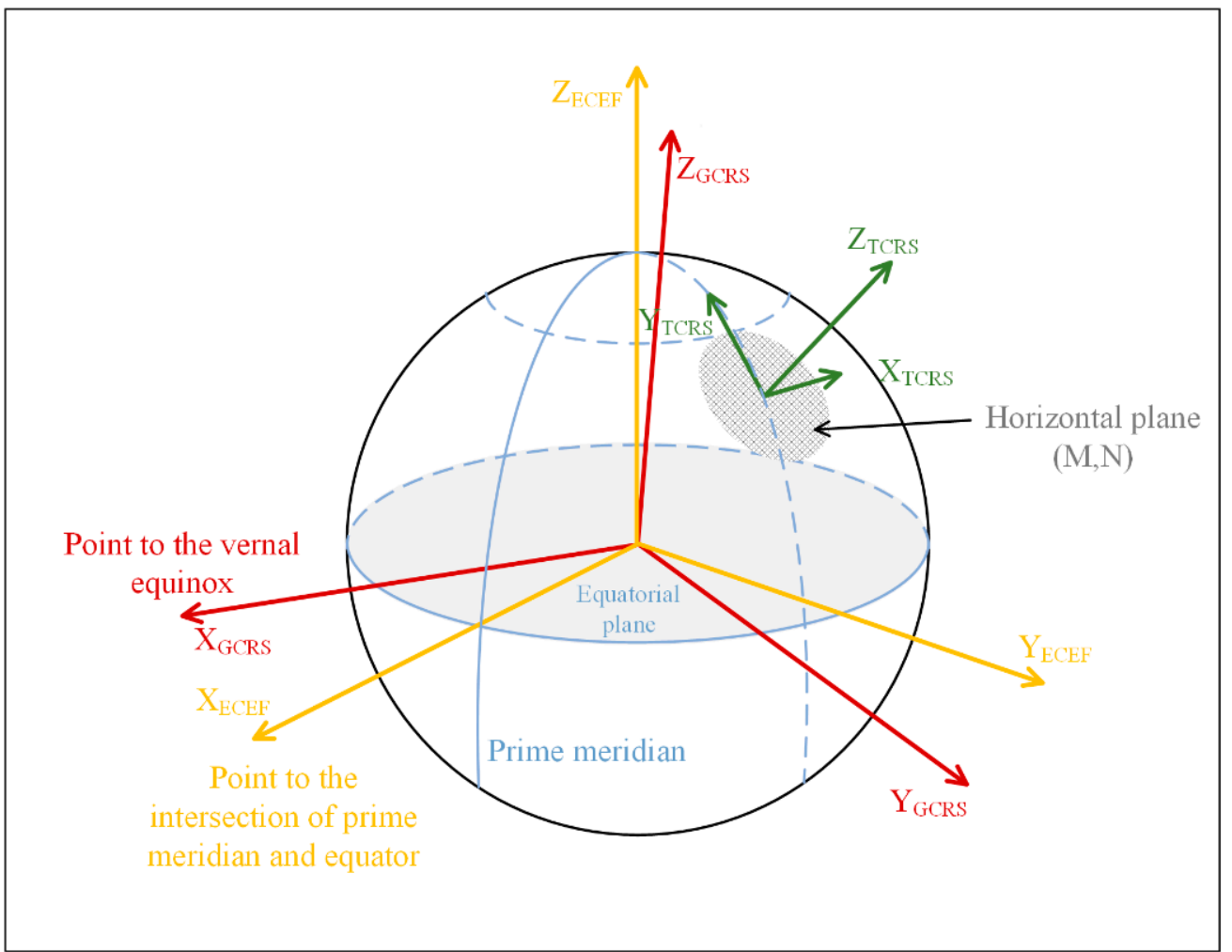

Figure 4. Diagram of Earth showing the relationship of three coordinate systems.

\subsubsection{Calculation of the Geometrical Parameters}

The TCRS is a type of Cartesian coordinate system (CCS). In CCS, the elevation angle (EA), zenith angle (ZA), and azimuth angle (AA) are given by the following equation:

$$
\begin{gathered}
\mathrm{EA}=\arctan \left(\frac{S_{z}}{\sqrt{S_{x}^{2}+S_{y}^{2}}}\right) \\
\mathrm{ZA}=90^{\circ}-\mathrm{EA} \\
\mathrm{AA}=\arctan \left(\frac{S_{y}}{S_{x}}\right)
\end{gathered}
$$

where $S_{x}, S_{y}$, and $S_{z}$ represent positions of celestial bodies in TCRS. Through the coordinate conversion in Appendix B, we obtain the position of the Moon and Sun in TCRS, $\left(x_{m}, y_{m}, z_{m}\right)_{T C R S}$ and $\left(x_{s}, y_{s}, z_{s}\right)_{T C R S}$. Then, entering them into Equations (1)-(3), we get the elevation angles, zenith angles, and azimuth angles of the Moon and Sun for any grids in the Moon-viewed sunlit area.

By calculating EAs of the Moon and the Sun for each global observation grid, we mark all grids with EAs greater than zero degrees as " 1 ", and the rest as " 0 " to map out the Moon-viewed sunlit Earth.

\subsection{Anisotropic Factors from CERES/ERBE ADMs}

TOA flux is the radiant energy emitted, reflected, or scattered by the atmosphere per unit area. Flux is related to radiance $L$ as follows:

$$
F\left(\theta_{S}\right)=\int_{0}^{2 \pi} \int_{0}^{\pi / 2} L\left(\theta_{S}, \theta_{V}, \phi\right) \cos \theta_{V} \sin \theta_{V} d \theta_{V} d \phi
$$

where $\theta_{S}$ is the solar zenith angle, $\theta_{V}$ is the observer viewing zenith angle, and $\phi$ is the relative azimuth angle defining the azimuth angle position of the observer relative to the 
solar plane (Figure 5). It is difficult to measure the upwelling radiance from any direction instantaneously, and thus flux cannot be derived by Equation (4). An ADM (angular distribution model) is a function $R$ that provides anisotropic factors for determining the TOA flux from an observed radiance as follows:

$$
F\left(\theta_{S}\right)=\frac{\pi L\left(\theta_{S}, \theta_{V}, \phi\right)}{R\left(\theta_{S}, \theta_{V}, \phi\right)}
$$



Figure 5. Diagram of Earth showing the sensor, Sun, and target geometry.

According to [35], $R$ is obtained from a set of predetermined empirical ADMs defined for several scene types with distinct anisotropic characteristics. Each ADM is constructed from a large ensemble of radiance measurements that are sorted into discrete angular bins and parameters that define an ADM scene type. The ADM anisotropic factors for a given scene type $(j)$ are given by:

$$
R_{j}\left(\theta_{S i}, \theta_{V k}, \phi_{l}\right)=\frac{\pi \bar{L}_{j}\left(\theta_{S i}, \theta_{V k}, \phi_{l}\right)}{F_{j}\left(\theta_{S i}\right)}
$$

where $\bar{L}_{j}$ is the average radiance in an angular bin $\left(\theta_{S i}, \theta_{V k}, \phi_{l}\right)$ and $F\left(\theta_{S}\right)$ is the upwelling flux in a solar zenith angle bin $\theta_{S i}$. The set of angles $\left(\theta_{S i}, \theta_{V k}, \phi_{l}\right)$ corresponds to the midpoint of a discrete angular bin defined by $\left[\theta_{S i} \pm\left(\Delta \theta_{S}\right) / 2, \theta_{V k} \pm\left(\Delta \theta_{V}\right) / 2, \phi_{l} \pm(\Delta \phi) / 2\right]$, where $\Delta \theta_{S}, \Delta \theta_{V}$, and $\Delta \phi$ represent the angular bin resolution. If the radiance is Lambertian, that is, independent of viewing zenith angles and azimuth angles, then $R=1$. In principle, the radiance is non-Lambertian, varying with viewing zenith angles and azimuth angles, then $R \neq 1$.

The Earth Radiation Budget Experiment (ERBE) ADM is constructed using data primarily from the Earth Radiation Budget (ERB) radiometer onboard Nimbus 7. The scene types selected for the ERBE SW ADM include twelve scene types: nine basic types and three mixed types. Four levels of cloud coverage are included: clear sky (0 to 5 percent), partly cloudy (5 to 50 percent), mostly cloudy (50 to 95 percent), and overcast (95 to 100 percent) $[39,40]$. Table 1 gives a complete list of scene types, and a set of angular bins are given in Table 2. Figure 6 shows the anisotropic factors of four major clear-scene types. The X-axis is the viewing zenith angle, the Y-axis is the solar zenith angle, and the $Z$-axis is the anisotropic factors. Different colors represent different relative 
azimuth angles. Grey dots are the projections on the $\mathrm{X}-\mathrm{Z}$ plane and $\mathrm{Y}-\mathrm{Z}$ plane. It can be seen that the anisotropic factors of the "clear ocean" type are larger than factors of other types, especially when the solar zenith angles and viewing zenith angles are close to $90^{\circ}$, relative azimuth angles are close to $0^{\circ}$, and the anisotropic factors are much larger. Compared with other scene types, the factors of the "clear desert" type vary with angular bins more gradually.

One of the largest uncertainties in global climate models is the representation of how clouds and aerosols influence ERB [35]. Clouds, which cover about two-thirds of the Earth, usually have two effects on ERB: a cooling effect and greenhouse effect. The former means that clouds block shortwave radiation from reaching the ground by reflecting and scattering solar radiation, thereby causing the surface to cool down [41]. The latter means that clouds block shortwave radiation reflected by the ground while emitting longwave radiation downwards, thereby heating the ground [42]. Recently, Shang et al. found by simulation that cloud influence on outgoing shortwave radiation is relatively small in the Moon-based view [43]. In this paper, we lay priority on the anisotropy of the surface reflection. Therefore, only clear sky scene types (cloud cover $<5 \%$ ) are considered as our research object.

Table 1. Scene Types for ERBE SW ADM.

\begin{tabular}{cc}
\hline Scene & Cloud Cover (\%) \\
\hline Clear over ocean & $0-5$ \\
Clear over land & $0-5$ \\
Clear over snow & $0-5$ \\
Clear over desert & $0-5$ \\
Clear over land-ocean mix & $0-5$ \\
Partly cloudy over ocean & $5-50$ \\
Partly cloudy over land or desert & $5-50$ \\
Partly cloudy over land-ocean mix & $5-50$ \\
Mostly cloudy over ocean & $50-95$ \\
Mostly cloudy over land or desert & $50-95$ \\
Mostly cloudy over land-ocean mix & $50-95$ \\
Overcast & $95-100$ \\
\hline
\end{tabular}

Table 2. Angular bin definitions for ERBE ADM.

\begin{tabular}{cccccc}
\hline Bin & $\begin{array}{c}\text { Solar Zenith } \\
\text { Angle (deg) }\end{array}$ & Bin & $\begin{array}{c}\text { Viewing Zenith } \\
\text { Angle (deg) }\end{array}$ & Bin & $\begin{array}{c}\text { Relative Azimuth } \\
\text { Angle (deg) }\end{array}$ \\
\hline 1 & $0-25.84$ & 1 & $0-15$ & 1 & $0-9$ \\
2 & $25.84-36.87$ & 2 & $15-27$ & 2 & $9-30$ \\
3 & $36.87-45.57$ & 3 & $27-39$ & 3 & $30-60$ \\
4 & $45.57-53.13$ & 4 & $39-51$ & 4 & $60-90$ \\
5 & $53.13-60.00$ & 5 & $51-63$ & 5 & $90-120$ \\
6 & $60.00-66.42$ & 6 & $63-75$ & 6 & $120-150$ \\
7 & $66.42-72.54$ & 7 & $75-90$ & 7 & $150-171$ \\
8 & $72.54-78.46$ & & & 8 & $171-180$ \\
9 & $78.46-84.26$ & & & & \\
10 & $84.26-90.00$ & & & & \\
\hline
\end{tabular}






(a): Ocean



(c): Desert



(b): Land

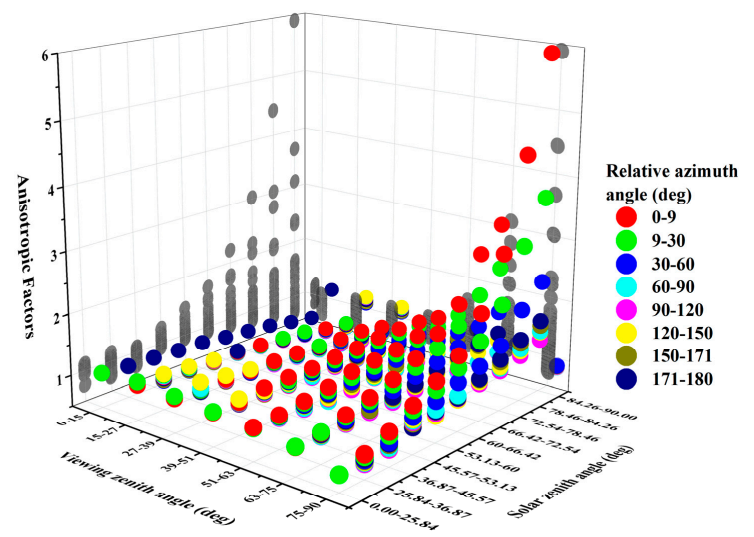

(d): Snow

Figure 6. Anisotropic factors of different scene types and incidence-viewing geometry. Grey dots are the projections on the $\mathrm{X}-\mathrm{Z}$ plane and $\mathrm{Y}-\mathrm{Z}$ plane, respectively.

\subsection{Estimation of Earth's OSR in the Lunar Direction}

ADM supplies a set of anisotropic factors at various incident-viewing geometries, so it can be used to convert the observed radiance to the TOA radiant flux, according to Equation (5). Inversely, it can also be used to simulate radiance from the TOA radiant flux. The radiance measured from a certain region above TOA could be calculated as:

$$
\hat{I}\left(\theta_{S}, \theta_{V}, \phi, j\right)=\frac{R\left(\theta_{S}, \theta_{V}, \phi, j\right) \hat{F}\left(\theta_{S}, j\right)}{\pi}
$$

where $\hat{F}$ is the TOA radiant flux from a region and $\hat{I}$ is the radiance of this region under a certain incidence-viewing geometry. The geometric parameters are calculated from NASA JPL ephemeris at given time, including Sun elevation angle, Moon elevation angle, and relative azimuth angle, presented in Section 2.1. Scene types data are from MCD12C1 [44], one of the MODIS Land Cover products. The surface of a TOA region is defined as its directly projected area on Earth's surface [35,45]. TOA shortwave radiant flux $\hat{F}$ is provided by CERES SYN1 deg products. The CERES project provides satellite-based observations of ERB and a comprehensive set of ERB data products. The data are now widely used to help us better understand ERB [46]. SYN1 deg products include computed TOA and surface fluxes and fluxes at four atmospheric pressure levels $(70,200,500$, and $850 \mathrm{hPa}$ ) along with monthly, monthly 1-hourly, daily, 3-hourly, and hourly products, and the spatial resolution is $1^{\circ} \times 1^{\circ}$ [47]. Hourly clear sky TOA flux data are used to simulate instantaneous EOSRiLD. 
According to the zero-order radiative transfer model for a mixed surface, the mean radiance of MsR (Moon-viewed sunlit region) is the summation of the regional radiance weighted by a factor as follows:

$$
\bar{I}(t)=\sum_{i \in N} f_{i} \hat{I}\left(\theta_{S i}, \theta_{V i}, \phi_{i}, j_{i}\right)
$$

where $N$ is all grids of MsR, $\hat{I}\left(\theta_{S i}, \theta_{V i}, \phi_{i}, j_{i}\right)$ is the outgoing radiance from $i$ th grid, $\theta_{S i}, \theta_{V i}, \phi_{i}$ is the incidence-viewing geometry of the $i$ th grid observed from the Moon at a certain time $t$, and $j_{i}$ is the scene type of the $i$ th grid at $t$. In this work, we only consider clear-sky conditions; hence $j_{i}$ is considered constant, not varying with time. The weight factor can be calculated as:

$$
f_{i}=\frac{A_{i} \cos \theta_{V i} D_{i}^{-2}}{\sum_{i=1}^{N} A_{i} \cos \theta_{V i} D_{i}^{-2}}
$$

where $A_{i}$ is the area of the $i$ th grid, and $D_{i}$ is the distance from grid $i$ to the Moon's center, derived from $\left(x_{m}, y_{m}, z_{m}\right)_{T C R S}$ and $\left(x_{i}, y_{i}, z_{i}\right)_{T C R S}$ in Section 2.1.

Above all, the simulation of instantaneous EOSRiLD is obtained from Equation (8), by calculating the mean radiance in the lunar direction of MsR.

\section{Results}

We first calculated the Moon zenith angles (MZA) for each CERES grid and determined the Moon-viewed sunlit region (MsR). Then, we calculated the global mean shortwave radiance in the lunar direction (EOSRiLD) by Equation (8) in Section 2.3. Finally, we simulated EOSRiLD over different periods to explore the regularity of its changes.

\subsection{Distribution of Moon-Viewed Sunlit Region}

Because CERES TOA shortwave flux data has been divided into sunlit and non-sunlit regions, we only calculated MZA in this part to simulate MsR. As shown in Figure 7, we selected three moments to show the changes in MsR. The images in the left column $((a, c, e))$ show the hourly global TOA shortwave flux from CERES, and in the right column $((\mathrm{b}, \mathrm{d}, \mathrm{f}))$ show the hourly TOA shortwave flux in the Moon-viewed region at the same time. The sunlit area, illustrated as the positive shortwave radiant flux, moves from west to east on the Earth's surface within one day due to the Earth's rotation, in Figure 7a,c,e. Earth's obliquity leads to the movement of the sunlit area between the northern and southern hemispheres. The Moon elevation angle and Sun elevation angle of the grid should both be greater than $0^{\circ}$ in the MsR; therefore, only part of Earth's sunlit region is visible to the Moon, shown in Figure 7b,d,f. As the Moon revolves around Earth from west to east, the Moon-viewed region also moves from west to east. Above all, Earth's rotation and Moon's revolution determine the MsR, where the area and scene types vary with time. As shown in Figure 8, we simulated the changes in the area of different types in 2019. The number of grids in MsR represents the area size. Because the amount of land-ocean mix is small, it is not shown in Figure 8. We found that the areas of ocean, land, and desert change periodically with the area of MsR, and the ocean area is much larger than the others. 

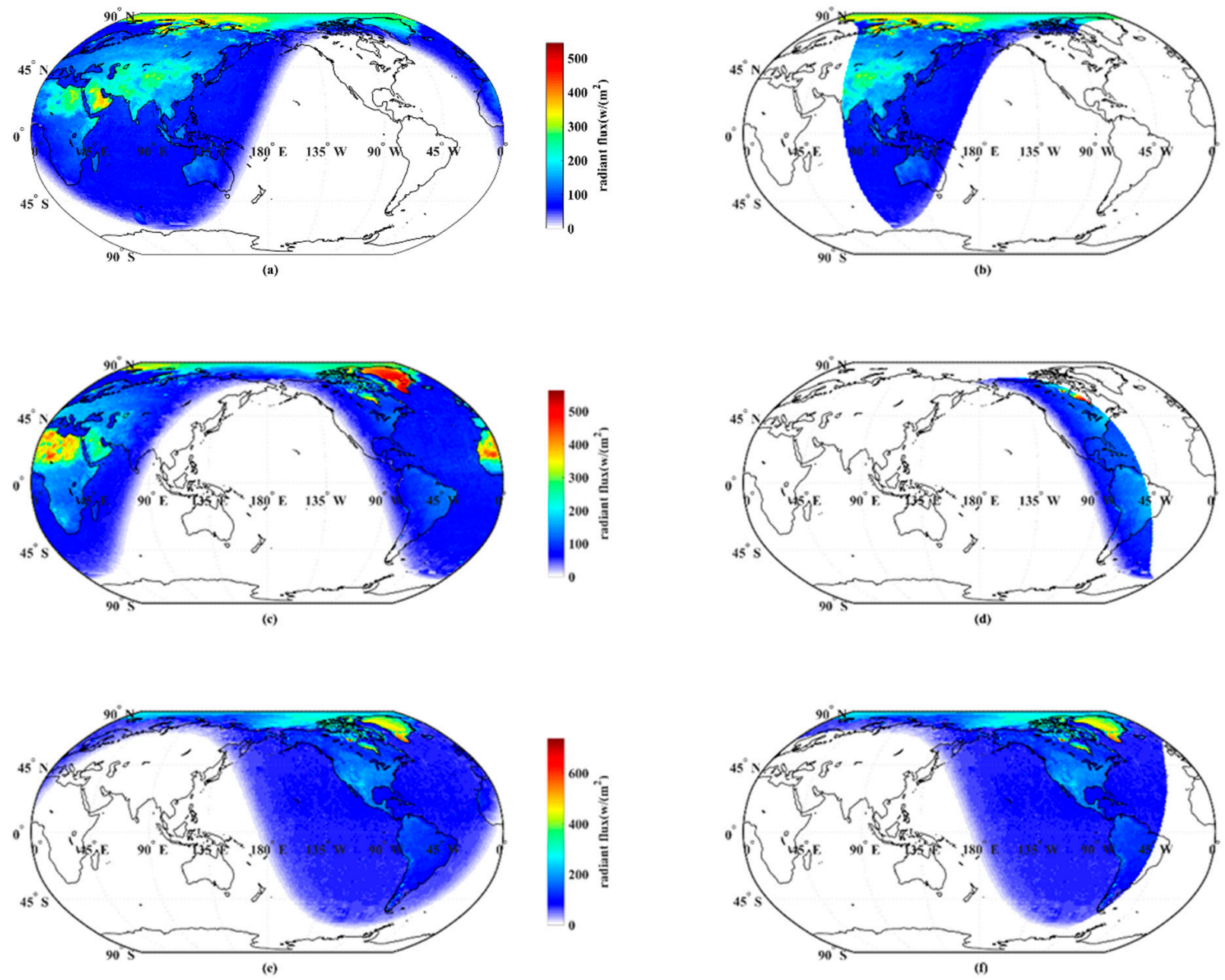

Figure 7. Hourly global TOA shortwave flux from CERES (images in the left column) and hourly TOA shortwave flux in the Moon-viewed sunlit region (images in the right column). The times of each image are: (a,b) 10 June 2019 06:30:14; (c,d) 21 June 2019 12:30:14; and (e,f) 30 June 2019 18:30:14.

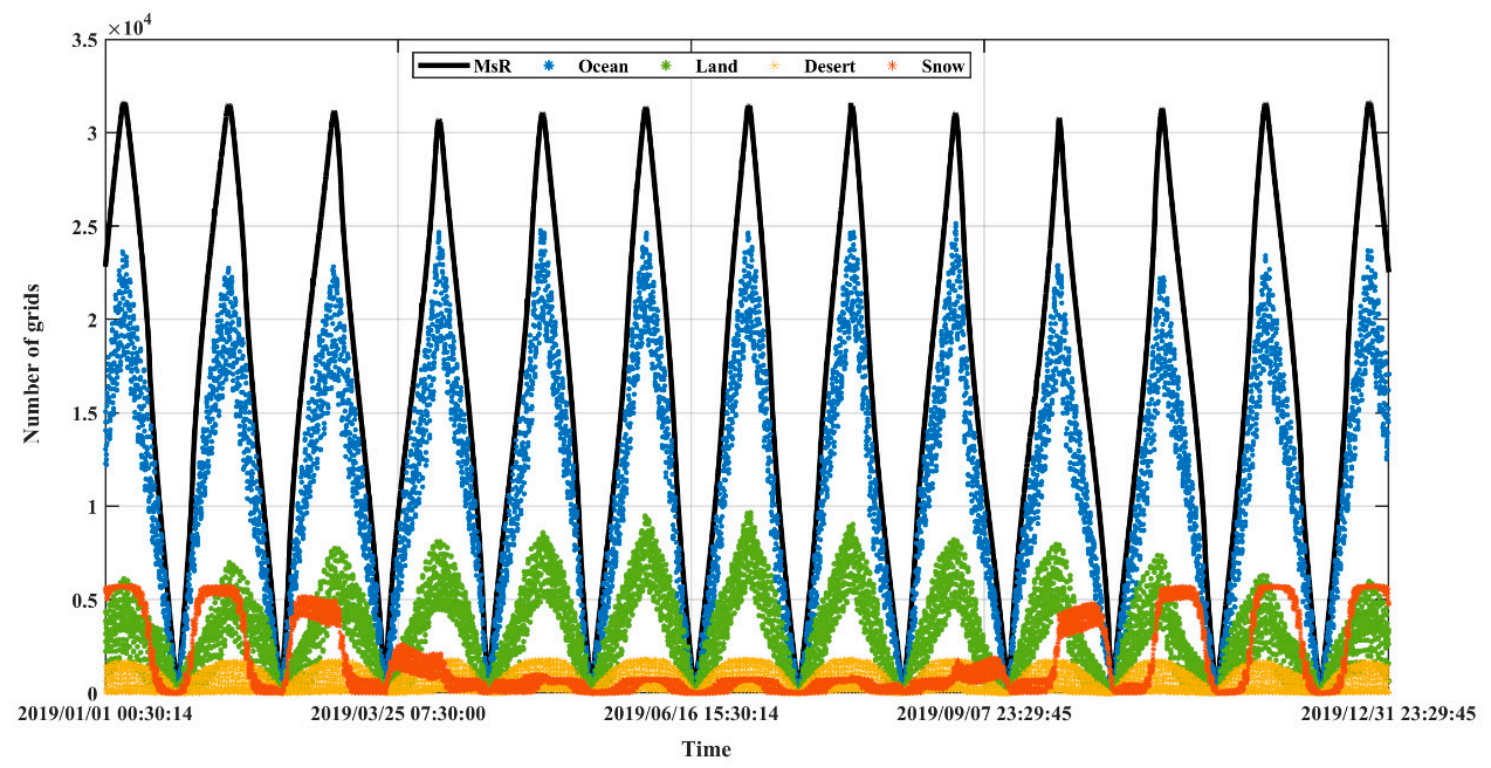

Figure 8. Number of grids of four scene types, ocean, land, desert, and snow, in the Moon-based sunlit region (MsR). 


\subsection{Anisotropic EOSRiLD over Different Periods}

From Figure 8, it is apparent that the areas of MsR change periodically. Due to EOSRiLD being simulated based on the MsR, we want to determine if there is also a periodicity in the change of EOSRiLD. Therefore, we simulated the EOSRiLD-based CERES data from 2000 to 2020 over three periods, considering both anisotropic $(R \neq 1)$ and isotropic $(R=1)$ conditions. On the one hand, the purpose is to explore the periodicity, on the other hand, it is to compare the difference between anisotropy and isotropy. If the difference is small, we could regard the surface reflection as isotropic in the later research on the Earth's radiation budget based on the Moon, but not the opposite.

\subsubsection{Anisotropic EOSRiLD over Earth's Rotation Period}

We simulated the instantaneous EOSRiLD from 2000 to 2020 over Earth's rotation period, under two conditions (anisotropy and isotropy) and randomly selected four days in 2016 (leap year) and 2019 (common year) as examples to display the differences between two conditions, as shown in Figure 9. It is apparent that the trend of the anisotropic and isotropic EOSRiLD in Earth's rotation period is similar. Moreover, most of the anisotropic values are larger than those of isotropy. The maximum value of anisotropy is much larger than the value of isotropy at the same time in Figure 9. We also found that sometimes the values of isotropy are slightly larger than those of anisotropy, for example, 14 February 2016 and 9 April 2019. However, we didn't find a certain rule between the changes in anisotropy and isotropy and time. For instance, the maximum anisotropic value in 2016 was at the end of November, but the maximum in 2019 was at the beginning of June. Therefore, we need to simulate the changes in EOSRiLD over larger time periods.

\subsubsection{Anisotropic EOSRiLD over Earth's Revolution Period}

In this section, we compared the daily differences, which means that we viewed the average of $24 \mathrm{~h}$ as one day's value, as shown in Figure 10. The trend of the daily anisotropy and isotropy EOSRiLD over Earth's revolution period is similar, showing a regular cycle. Moreover, we found anisotropic values were larger than isotropic values in most cases, and the highest daily anisotropy EOSRiLD reached $180 \mathrm{w} /\left(\mathrm{m}^{2} \cdot \mathrm{sr}\right)$, which is almost four times the daily isotropy EOSRiLD at the same time. It is apparent that the EOSRiLDs, regardless of the anisotropy and isotropy, show a regular cycle, and the number of cycles is about 12 times a year. In the lunar calendar, there are exactly 12 synodic cycles in one year. As such, we speculated there may be a relationship between this cycle and the lunar revolution period. 



Figure 9. Simulation of hourly EOSRiLD over Earth's rotation period in 2016 and 2019. 


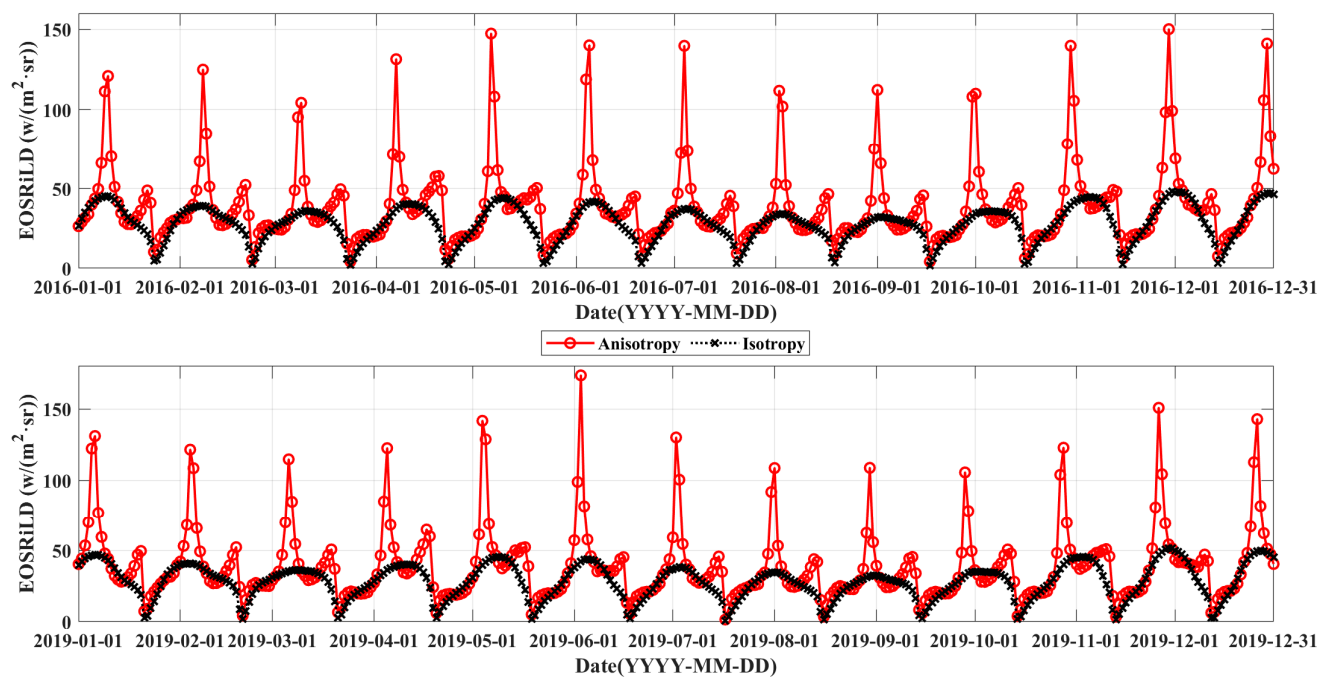

Figure 10. The simulation of daily EOSRiLD over Earth's revolution period in 2016 and 2019.

\subsubsection{Anisotropic EOSRiLD over the Synodic Month Cycle}

People usually use synodic moons to describe the average period of the Moon's revolution around Earth relative to the Sun, which is the average period of lunar phases, about 29.53 days. In this section, we simulated the EOSRiLD over the synodic month cycle. Since solar and lunar calendars are different, we made a comparison table to show results clearly during 2016-2017 and 2019-2020 (Appendix C). Based on the lunar calendar, we obtained the 12 lunar months' simulation results of 2019-2020 (Figure 11). We found that the changes in EOSRiLD were consistent with the synodic month cycle and the greatest difference between anisotropy and isotropy in each cycle is at the beginning and end of the lunar month. Regardless of isotropy and anisotropy, the values are roughly symmetrical in a lunar month, decreasing in the first half of the month and increasing in the second half of the month. The minimum value in each cycle occurs in the middle days, and the maximum values in each cycle occur in the first and last days. However, there is a small peak close to the middle of a cycle for the anisotropic EOSRiLD, which will be discussed in Section 4.2.
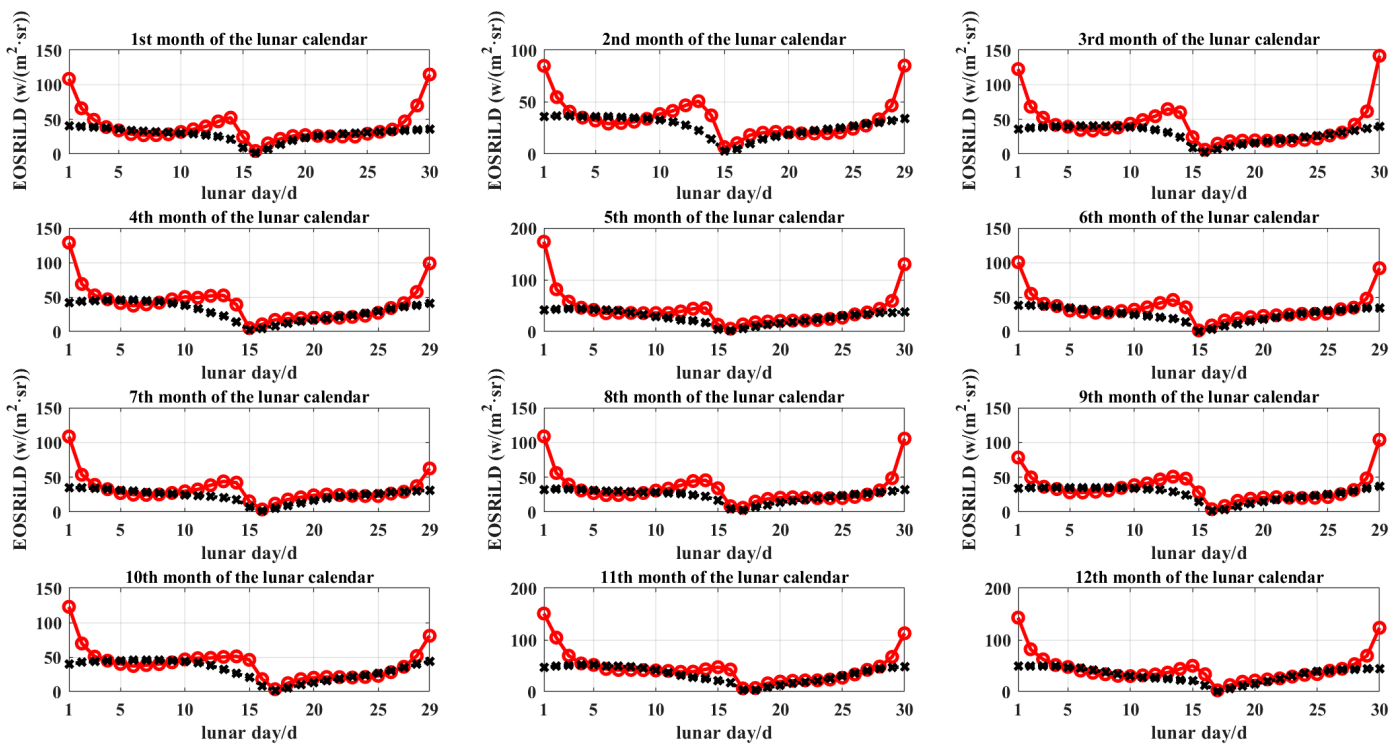

Figure 11. Twelve lunar month simulation of daily EOSRiLD from 5 February 2019 to 24 January 2020 based on the lunar calendar. 


\section{Discussion}

\subsection{Impact of the Area of Moon-Viewed Sunlit Region on Anisotropic EOSRiLD}

As mentioned earlier, Earth's rotation and Moon's revolution determine the MsR. In Figure 8, the area of MsR also presents a regular cycle. In order to determine whether the periodic changes are consistent for EOSRiLD and the area of MsR, we compared them based on the lunar calendar, as shown in Figure 12. Red lines represent the area, and black solid and dashed lines represent anisotropic and isotropic EOSRiLD. The area also shows the same period as EOSRiLD with the revolution of the Moon. Since isotropic values are not affected by anisotropic factors, we focused on comparing the isotropic EOSRiLD with the area of MsR. Therefore, we calculated isotropic values and areas from 2000 to 2020 to fit the correlation between the isotropic EOSRiLD and area, and the correlation coefficient is 0.85, shown in Figure 13. Above all, the periodicity of EOSRiLD is caused by the revolution of the Moon, which affects the area of MsR and then the values of EOSRiLD. As the area increases, the values of EOSRiLD also increase.

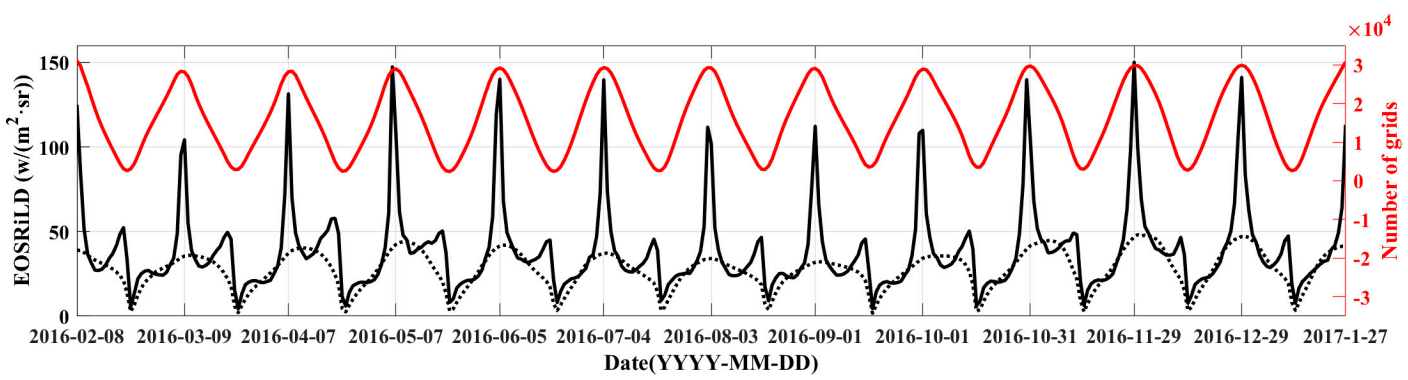

- Anisotropy …...... Isotropy - MsR

$\times 10^{4}$

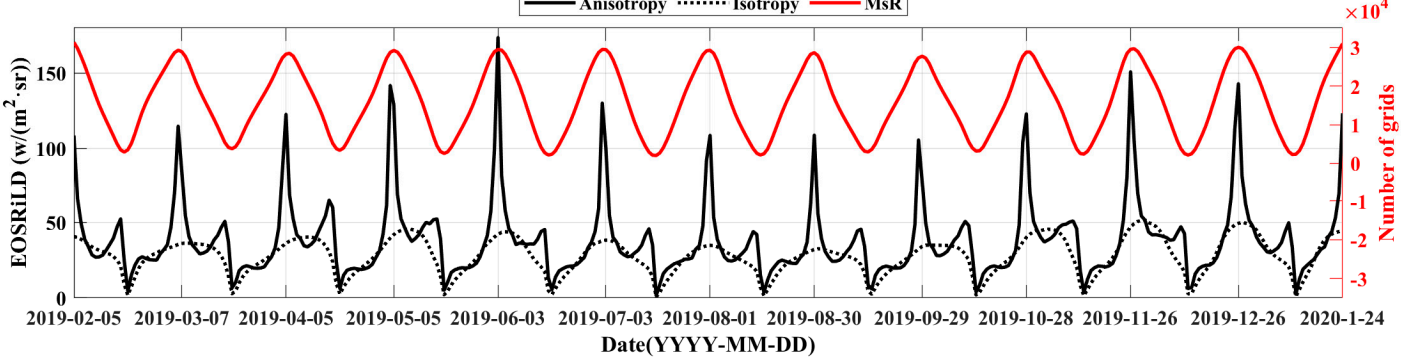

Figure 12. Changes in daily EOSRiLD and areas of MsR in 2016 and 2019.

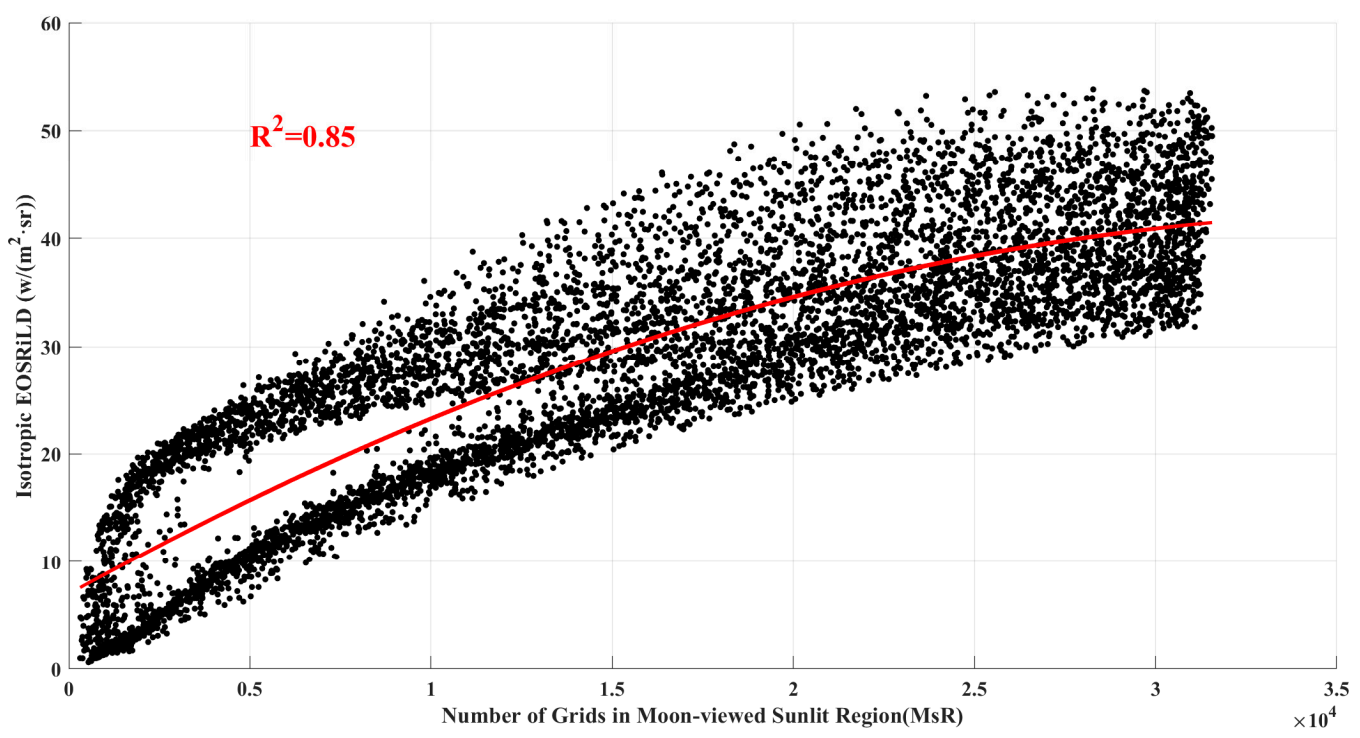

Figure 13. Scatter plot of daily isotropic EOSRiLD and number of grids in MsR from 2000 to 2020. 


\subsection{Impact of the Anisotropic Factors on Anisotropic EOSRiLD}

If anisotropic EOSRiLD were only affected by area of MsR, it would be the same as the isotropic EOSRiLD. However, it is apparent that there are two differences between the anisotropic and isotropic values. On the one hand, anisotropic values are larger than isotropic values in the first and last days of each lunar month. On the other hand, there is a small peak close to the middle of each cycle for the anisotropic EOSRiLD, as shown in Figures 10-12. Therefore, we performed the analysis on the other two variables in the model, scene types, and incident-viewing angular bins.

\subsubsection{Impact of Scene Types on Anisotropic EOSRiLD}

In this section, our main focus is to compare the anisotropy of different scene types in each cycle. To this end, we divided the EOSRiLD calculated from the Equation (8) into five parts according to the scene types (ocean, land, desert, snow, and land-ocean mix, as shown in Table 1) under anisotropy and isotropy conditions. The core is expressed clearly through the following formula (Equations (10) and (11)). Since the distribution of the land-ocean mix is much smaller than others, we neglected its values in this section:

$$
\begin{aligned}
& \bar{I}=\overline{I_{1}}+\overline{I_{2}}+\overline{I_{3}}+\overline{I_{4}} \\
& I^{\prime}=I_{1}^{\prime}+I_{2}^{\prime}+I_{3}^{\prime}+I_{4}^{\prime}
\end{aligned}
$$

where $\bar{I}$ and $I^{\prime}$ represent the instantaneous anisotropic EOSRiLD and isotropic EOSRiLD, $I_{1}, I_{2}, I_{3}$, and $I_{4}$ represent ocean, land, desert, and snow, respectively. Through the research in the previous section, the periodicity of EOSRiLD is caused by the revolution of the Moon. Therefore, we calculated all EOSRiLD between March 2000 (starting time of CERES data) and March 2020, divided into $240(12 \times 20)$ cycles in the light of lunar calendar and took the average. Then, we obtained the average over a period for each scene type, as shown in Figure 14. To compare the anisotropic and isotropic differences in scene types distinctly, we propose to use the difference ratio to measure it (Equation (12)), where $j$ represents scene types and the number represents the type consistent with the above.

$$
\mathrm{r}_{j}=\frac{\overline{I_{j}}}{\bar{I}_{j}^{\prime}}
$$



Figure 14. Cont. 

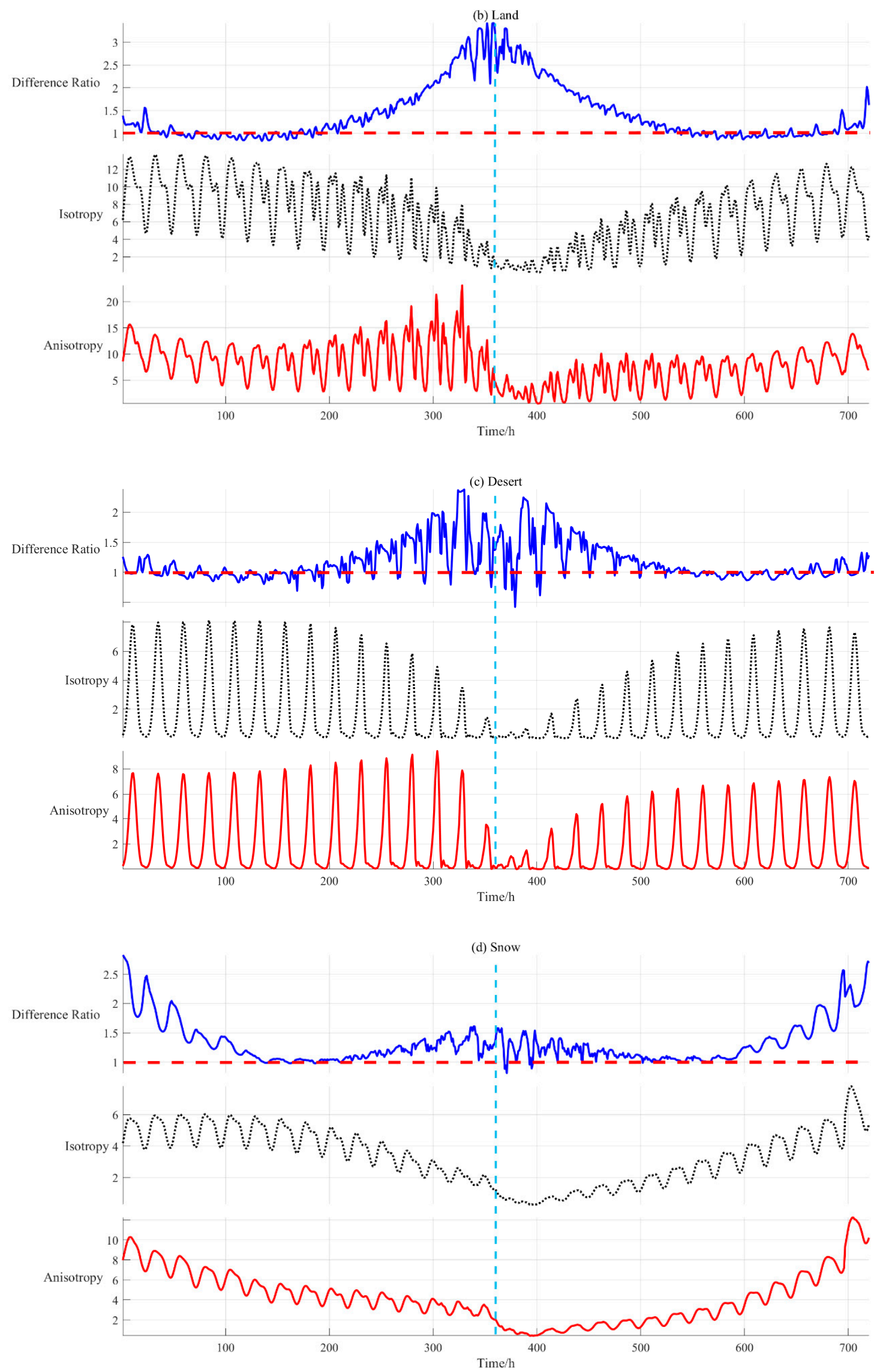

Figure 14. Comparison of the anisotropic and isotropic differences in scene types. 
As can be seen from Figure 14, the anisotropy of different scene types behaves with some similarities and some differences in a cycle. In general, no matter what kind of scene type, whether it is isotropic, anisotropic EOSRiLD, or a different ratio, they all show a certain symmetry. For ocean, its maximum anisotropic EOSRiLD is much larger than the others' maximum. On the one hand, this is because the area of ocean in MsR is much larger than others, as shown in Figure 8. On the other hand, the different ratios of ocean are basically more than one, which means the anisotropic characteristic of ocean is significant. Furthermore, the trend of anisotropy in Figure 14a is in line with that of Figure 11. This means that ocean plays an irreplaceable role in all scene types. For land and desert, although the values of land are a bit larger than the values of desert, the trends in both are consistent. They all show that the different ratios are larger in the middle of the month, and the ratio is almost one at the beginning and end of the time periods. Therefore, in the later research, to simplify the model, we could try to combine land and desert into one scene type. For snow, its isotropy and anisotropy curves are more like the ocean's, but its values are much smaller. In addition, when comparing isotropy curves of four types, we find they are not perfectly symmetrical. They show that values in the first half of the middle month are larger than the second half. Since we used daily average data for the analysis in Figure 12, this asymmetry is weakened. However, in this section, we adopted hourly data to reflect the facts, which is more convincing. Based on the relationship between isotropic values and area of MsR, we could derive asymmetry of MsR leads to the asymmetry in isotropy curves. Last but not least, when comparing anisotropy curves of four types, except for snow, the values of the other three in the first half of the month were decreasing and then increasing with the decrease in the area of MsR. To determine the reason behind this, we need to analyze the angle parameters in the model.

Above all, the anisotropy of different scene types behaves differently in a cycle. They could be grouped into two categories. Ocean and snow are one group, where anisotropy is more obvious in the beginning, middle, and end of the months, but the values of ocean are much larger than snow. Land and desert are another group, where anisotropy is more obvious in the middle of the months, and values show little difference.

\subsubsection{Impact of Incident-Viewing Angular Bins on Anisotropic EOSRiLD}

To solve the question of why some anisotropic EOSRiLDs increase with the decrease in area of MsR, we assumed that all MsR are ocean, land, desert, or snow, which removes the effect of the size of scene types, and calculated the anisotropic EOSRiLD of each grid. The difference is that there is no need to add up the values of all grids as in Equation (8). Therefore, with this assumption, we could obtain four sets of data at the same time, named Ocean-EOSRiLD, Land-EOSRiLD, Desert-EOSRiLD, and Snow-EOSRiLD. Apart from the four sets, we combined the solar zenith angles (SZA), viewing zenith angles (VZA), and relative azimuth angles (RAA) at the same time calculated from Section 2.1.2, as shown in Figure 15. Next, we classified the SZA, VZA, and RAA as Table 2, which are divided into 10, 7, and 8 categories, respectively. As the last section, we calculated the average distribution of incident-viewing angular bins in a cycle from March 2000 to March 2020, as shown in Figure 16. Finally, we calculated the average EOSRiLD in each category for different scene types. To make the comparison clearer, the average EOSRiLD has been expanded 1000 times.

From Figure 16, the distribution of SZA is relatively uniform, VZA is mainly distributed in the range of 75-90 degrees and RAA is mainly distributed in the range of 9-60 degrees. We found that values of EOSRiLD and distributions of angular bins do not seem to show a direct relationship. Furthermore, Land-EOSRiLD, Desert-EOSRiLD, and Snow-EOSRiLD, do not change as much as the SZA and VZA changes, but Ocean-EOSRiLD is not so. However, there was one feature in common: they are all affected by the RAA. When the RAA is in the range of 171-180 degrees, the values of Land-EOSRiLD, DesertEOSRiLD, and Snow-EOSRiLD are much larger than in 0-9 degrees, especially the first two, which is the same feature shown in Figure 6. As for the Ocean-EOSRiLD curve, it is 
similar to a bowl, and the maximum EOSRiLD is in the range of 0-9 and 171-180 degrees. Considering the movement of the Sun and Moon, the relative azimuth angles between the Sun and Moon are close to $0^{\circ}$ at the beginning and end of a month and close to $180^{\circ}$ in the middle of a month. This is why the maximum anisotropic EOSRiLD in Figure 14a is at the start and end of a month, and values increase with the decrease in the area of MsR in the first half of the month in Figure $14 \mathrm{a}-\mathrm{c}$.

In summary, based on the Moon observation, even though the platform has a wide scope, the difference is still large between anisotropy and isotropy. In all scene types, ocean plays a leading role, which mainly comes from two aspects: one is its area is much larger, the second is its anisotropy is more obvious. As for SZA, VZA, and RAA, anisotropy of scene types is influenced more by RAA. Therefore, we still need to consider the anisotropic surface reflection based on the Moon observation.

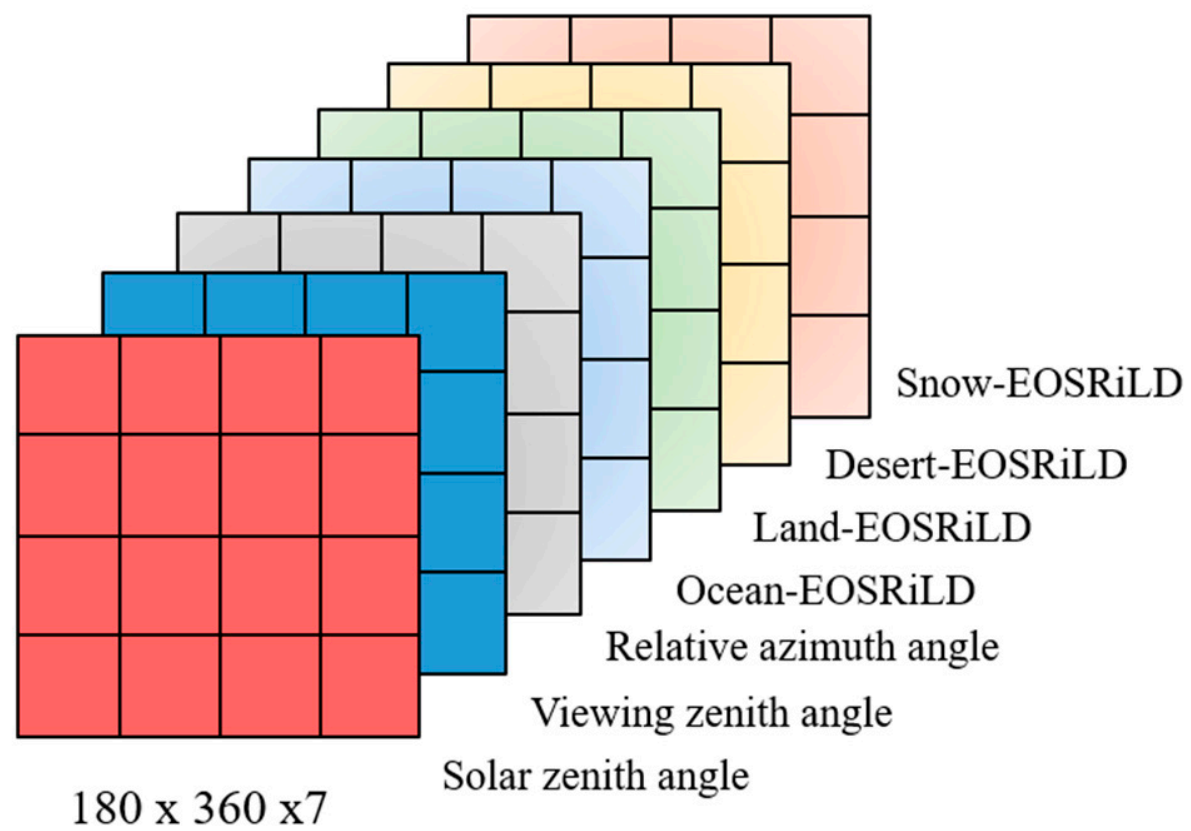

Figure 15. Schematic of sets of data at the same time. 

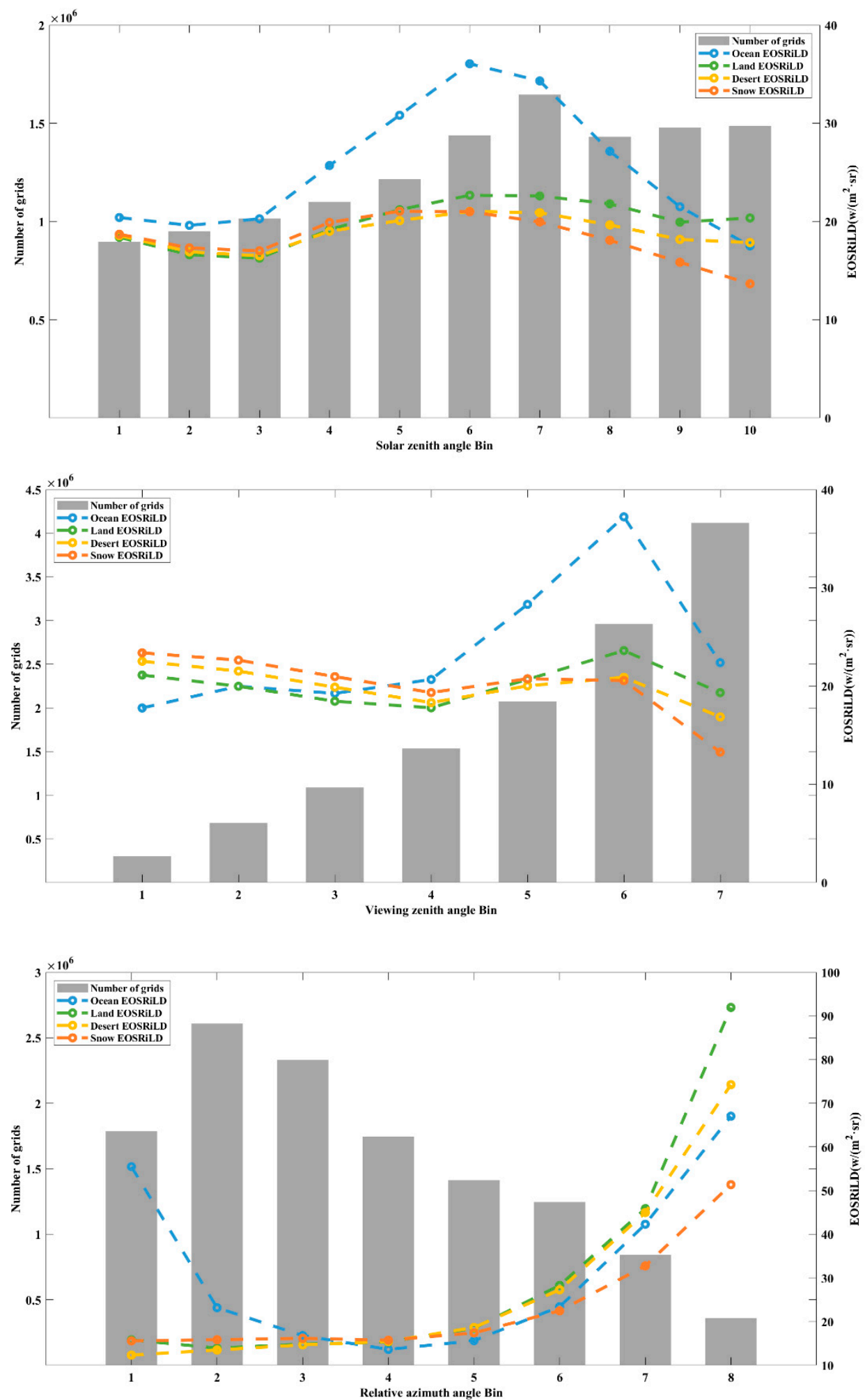

Figure 16. The average EOSRiLDs in different angular bins for different scene types.

\section{Conclusions}

The variation in the radiation budget at Earth's TOA represents the most fundamental metric defining the status of global climate change. Due to the complex anisotropic reflecting and scattering process in the Earth system, the estimation of total outgoing shortwave radiation is affected by significant uncertainties. Thus, the accurate estimation of Earth's shortwave outgoing radiance is of critical importance to improve the estimation of the ERB 
at TOA. Compared with artificial satellites, Moon-based sensors could provide large-scale, continuous, and long-term data for Earth radiation observations. The reflection of Earth's surface shows strong anisotropy, especially in the shortwave bands $(0.3-5 \mu \mathrm{m})$. However, there are few studies that regard shortwave reflection as anisotropic in ERB based on the Moon. In this paper, we first simulated the Moon-viewed sunlit region based on JPL ephemeris and established a model to estimate the EOSRiLD combined with ADM to study the influence of the anisotropic surface reflection on Earth's OSR in the lunar direction.

We discussed three time periods centered on EOSRiLD, Earth's rotation period, Earth's revolution period and synodic month cycle. The results show that EOSRiLDs, whether anisotropic or isotropic, represent periodic changes related to the Moon's revolution. In addition, the greatest difference between anisotropy and isotropy in each cycle is at the beginning and end of the lunar month, and there is a small peak close to the middle of each cycle for the anisotropic EOSRiLD. Hence, we firstly analyzed the impact of the area of MsR and anisotropic factors on the anisotropic EOSRiLD. Earth's rotation and Moon's revolution determine the MsR, but the area of MsR is only related to the Moon's revolution, which influences the periodic change in EOSRiLD. Then, we performed the analysis on the other two variables in the model, scene types, and incident-viewing angular bins. The anisotropy of different scene types behaves differently in a cycle. For ocean and snow, the anisotropy is more obvious in the beginning, middle, and end of the months. However, for land and desert, the anisotropy is more obvious in the middle of the month. These behaviors are mainly because RAA is different at different times in a cycle. In other words, RAA is the main cause for the difference between anisotropy and isotropy.

In conclusion, even if the Moon-based platform has a wide scope, the difference is still large between anisotropy and isotropy. Ocean plays a leading role in all scene types, and its anisotropy is more obvious. The anisotropy of scene types is influenced more by RAA. Therefore, we still need to consider the anisotropic surface reflection based on the Moon-based observation.

Author Contributions: H.G., Y.D., and J.W. designed this study. J.W. and H.S. conducted all data processing and visualization. T.L., L.L., and M.L. helped in investigation, data interpretation, and validation. J.W. wrote this paper. All authors have played a role in reviewing and editing this paper. All authors have read and agreed to the published version of the manuscript.

Funding: This research was funded by the National Natural Science Foundation of China (grant number 41590853, 41501403) and the Key Project of Frontier Science Research of the Chinese Academy of Sciences (QYZDY-SSW-DQC026).

Data Availability Statement: Not applicable.

Acknowledgments: We appreciate the NASA Jet Propulsion Laboratory for providing the free ephemeris data. We also thank Clouds and Earth's Radiant Energy System for providing the free flux data.

Conflicts of Interest: The authors declare no conflict of interest.

\section{Appendix A}

TOA

OSR

ERB

MS

MsR

LEO

ERBE

CERES

SORCE

GERB

NISTAR

DSCOVR
Top of atmosphere

Outgoing shortwave radiation

Earth radiation budget

Moon-based Sensor

Moon-viewed sunlit region

Low-Earth orbit

Earth Radiation Budget Experiment

Clouds and Earth's Radiant Energy System

Solar Radiation and Climate Experiment

Geostationary Earth Radiation Budget

National Institute of Standards and Technology Advanced Radiometer

Deep Space Climate Observatory 


$\begin{array}{ll}\text { OHC } & \text { Ocean heat capacity } \\ \text { EOSRiLD } & \text { Earth outgoing shortwave radiance in the lunar direction } \\ \text { GCRS } & \text { Geocentric Celestial Reference System } \\ \text { GCS } & \text { Geodetic Coordinate System } \\ \text { ECEF } & \text { Earth-centered Earth-fixed } \\ \text { TCRS } & \text { Topocentric Cartesian reference system } \\ \text { CCS } & \text { Cartesian coordinate system } \\ \text { EA } & \text { Elevation angle } \\ \text { ZA } & \text { Zenith angle } \\ \text { AA } & \text { Azimuth angle } \\ \text { ADM } & \text { Angular distribution model } \\ \text { RAA } & \text { Relative azimuth angle } \\ \text { MZA } & \text { Moon zenith angle }\end{array}$

\section{Appendix B}

Detailed descriptions of transformation of coordinate systems are as follows:

(1) GCRS to ECEF

The conversion equation is:

$$
[E C E F]=W^{-1}(t) R^{-1}(t) Q^{-1}(t)[G C R S]
$$

where $t$ is time, and $Q(t), R(t)$, and $W(t)$ are the rotation matrices of Earth's nutation and procession, and rotation and pole shift at a given time $t$, respectively [48]. The positions of the Moon and the Sun in JPL can be converted to $\left(X_{m}, Y_{m}, Z_{m}\right)_{E C E F}$ and $\left(X_{s}, Y_{s}, Z_{s}\right)_{E C E F}$.

\section{(2) GCS to ECEF}

Any grid $i$ of Earth observation grids is expressed in its center's latitude and longitude $\left(M_{i}, N_{i}\right)$, and we should convert it to ECEF. Without considering the altitude, the conversion relationship [49] is:

$$
\left[\begin{array}{c}
X_{i} \\
Y_{i} \\
Z_{i}
\end{array}\right]_{E C E F}=\left[\begin{array}{c}
R_{E} \cos \left(N_{i}\right) \cos \left(M_{i}\right) \\
R_{E} \cos \left(N_{i}\right) \sin \left(M_{i}\right) \\
R_{E} \sin \left(M_{i}\right)
\end{array}\right]
$$

where $R_{E}$ is Earth's radius, and $\left[X_{i}, Y_{i}, Z_{i}\right]_{E C E F}^{T}$ is observation grid $i$ in ECEF.

\section{(3) ECEF to TCRS}

First, we move the origin from Earth's center of mass to the observation point $i$ on the Earth's surface in ECEF. Secondly, we rotate the coordinate around the Z-axis and X-axis. The conversion relationship is [50]:

$$
\left[\begin{array}{c}
x \\
y \\
z
\end{array}\right]_{T C R S}=R_{X}\left(90^{\circ}-N\right) R_{Z}\left(90^{\circ}+M\right)\left(\left[\begin{array}{l}
X \\
Y \\
Z
\end{array}\right]_{E C E F}-\left[\begin{array}{c}
X_{i} \\
Y_{i} \\
Z_{i}
\end{array}\right]_{E C E F}\right)
$$

where $[x, y, z]_{T C R S}^{T}$ is the TCRS position of the $[X, Y, Z]_{E C E F}^{T}$ point, $R_{X}\left(90^{\circ}-N\right)$ and $R_{Z}\left(90^{\circ}+M\right)$ respectively represent the coordinate rotation around the $X$-axis and $Z$-axis, given in Equations (A4) and (A5). Using multiplication, finally we get Equation (A6):

$$
\begin{aligned}
& R_{X}\left(90^{\circ}-N\right):\left(\begin{array}{ccc}
1 & 0 & 0 \\
0 & \cos \left(90^{\circ}-N\right) & \sin \left(90^{\circ}-N\right) \\
0 & -\sin \left(90^{\circ}-N\right) & \cos \left(90^{\circ}-N\right)
\end{array}\right) \\
& R_{Z}\left(90^{\circ}+M\right):\left(\begin{array}{ccc}
\cos \left(90^{\circ}+M\right) & \sin \left(90^{\circ}+M\right) & 0 \\
-\sin \left(90^{\circ}+M\right) & \cos \left(90^{\circ}+M\right) & 0 \\
0 & 0 & 1
\end{array}\right)
\end{aligned}
$$




$$
\left[\begin{array}{l}
x \\
y \\
z
\end{array}\right]_{T C R S}=\left(\begin{array}{ccc}
-\sin M & \cos M & 0 \\
-\sin N \cos M & -\sin N \sin M & \cos N \\
\cos N \cos M & \cos N \sin M & \sin N
\end{array}\right) \bullet\left(\left[\begin{array}{c}
X \\
Y \\
Z
\end{array}\right]_{E C E F}-\left[\begin{array}{c}
X_{i} \\
Y_{i} \\
Z_{i}
\end{array}\right]_{E C E F}\right)
$$

In Equation (A6), we convert the position of the Moon and Sun in ECEF, $\left(X_{m}, Y_{m}, Z_{m}\right)_{E C E F}$ and $\left(X_{S}, Y_{S}, Z_{S}\right)_{E C E F}$, to the position of the Moon and Sun in TCRS, $\left(x_{m}, y_{m}, z_{m}\right)_{T C R S}$ and $\left(x_{S}, y_{s}, z_{S}\right)_{T C R S}$

\section{Appendix C}

Table A1. Comparison between the solar and lunar calendars of 2016-2017 and 2019-2020.

\begin{tabular}{|c|c|c|c|}
\hline Solar Calendar & Lunar Calendar & Solar Calendar & Lunar Calendar \\
\hline $\begin{array}{l}8 \text { February } 2016 \\
5 \text { February } 2019\end{array}$ & 1st day of 1st month & $\begin{array}{l}8 \text { March } 2016 \\
5 \text { March } 2019\end{array}$ & Last day of 1st month \\
\hline $\begin{array}{l}9 \text { March } 2016 \\
7 \text { March } 2019\end{array}$ & 1st day of 2nd month & $\begin{array}{l}6 \text { April } 2016 \\
4 \text { April } 2019\end{array}$ & $\begin{array}{l}\text { Last day of 2nd } \\
\text { month }\end{array}$ \\
\hline $\begin{array}{l}7 \text { April } 2016 \\
5 \text { April } 2019\end{array}$ & 1st day of 3rd month & $\begin{array}{l}5 \text { May } 2016 \\
4 \text { May } 2019\end{array}$ & Last day of 3rd month \\
\hline $\begin{array}{l}6 \text { May } 2016 \\
5 \text { May } 2019\end{array}$ & 1st day of 4 th month & $\begin{array}{l}4 \text { June } 2016 \\
2 \text { June } 2019\end{array}$ & Last day of 4 th month \\
\hline $\begin{array}{l}5 \text { June } 2016 \\
3 \text { June } 2019 \\
\end{array}$ & 1st day of 5th month & $\begin{array}{l}3 \text { July } 2016 \\
2 \text { July } 2019 \\
\end{array}$ & Last day of 5 th month \\
\hline $\begin{array}{l}4 \text { July } 2016 \\
\text { 3 July } 2019\end{array}$ & 1st day of 6th month & $\begin{array}{l}2 \text { August } 2016 \\
\text { 31 July } 2019\end{array}$ & Last day of 6th month \\
\hline $\begin{array}{l}3 \text { August } 2016 \\
1 \text { August } 2019\end{array}$ & 1st day of 7th month & $\begin{array}{l}31 \text { August } 2016 \\
29 \text { August } 2019\end{array}$ & Last day of 7th month \\
\hline $\begin{array}{c}1 \text { September } 2019 \\
30 \text { August } 2019\end{array}$ & 1st day of 8th month & $\begin{array}{l}30 \text { September } 2016 \\
28 \text { September } 2019\end{array}$ & Last day of 8th month \\
\hline $\begin{array}{c}1 \text { October } 2016 \\
29 \text { September } 2019\end{array}$ & 1st day of 9th month & $\begin{array}{l}30 \text { October } 2016 \\
27 \text { October } 2019\end{array}$ & Last day of 9th month \\
\hline $\begin{array}{l}31 \text { October } 2016 \\
28 \text { October } 2019\end{array}$ & 1st day of 10th month & $\begin{array}{l}28 \text { November } 2016 \\
25 \text { November } 2019\end{array}$ & $\begin{array}{c}\text { Last day of } 10 \text { th } \\
\text { month }\end{array}$ \\
\hline $\begin{array}{l}29 \text { November } 2016 \\
26 \text { November } 2019\end{array}$ & 1st day of 11th month & $\begin{array}{l}28 \text { December } 2016 \\
25 \text { December } 2019\end{array}$ & $\begin{array}{l}\text { Last day of 11th } \\
\text { month }\end{array}$ \\
\hline $\begin{array}{l}29 \text { December } 2019 \\
26 \text { December } 2019\end{array}$ & 1st day of 12 th month & $\begin{array}{l}27 \text { January } 2017 \\
24 \text { January } 2020\end{array}$ & $\begin{array}{l}\text { Last day of } 12 \text { th } \\
\text { month }\end{array}$ \\
\hline
\end{tabular}

\section{References}

1. Von Schuckmann, K.; Palmer, M.D.; Trenberth, K.E.; Cazenave, A.; Chambers, D.P.; Champollion, N.; Hansen, J.E.; Josey, S.A.; Loeb, N.; Mathieu, P.P. An imperative to monitor Earth's energy imbalance. Nat. Clim. Change 2016, 6, 138-144. [CrossRef]

2. Trenberth, K.E.; Stepaniak, D.P. Covariability of Components of Poleward Atmospheric Energy Transports on Seasonal and Interannual Timescales. J. Clim. 2003, 16, 3691-3705. [CrossRef]

3. Trenberth, K.E.; Stepaniak, D.P. Seamless Poleward Atmospheric Energy Transports and Implications for the Hadley Circulation. J. Clim. 2003, 16, 3706-3722. [CrossRef]

4. Trenberth, K.E.; Fasullo, J.T.; Kiehl, J. Earth's Global Energy Budget. Bull. Am. Meteorol. Soc. 2009, 90, 311-323. [CrossRef]

5. Barkstrom, B.R.; Smith, G.L. The Earth Radiation Budget Experiment: Science and implementation. Rev. Geophys. 1986, 24, 379-390. [CrossRef]

6. Harries, J.; Crommelynck, D. The Geostationary Earth Radiation Budget Experiment on MSG-1 and its Potential Applications. Adv. Space Res. 1999, 24, 915-919. [CrossRef]

7. Wielicki, B.A.; Barkstrom, B.R.; Harrison, E.F.; III, R.B.L.; Smith, G.L.; Cooper, J.E. Clouds and the Earth's Radiant Energy System (CERES): An Earth Observing System Experiment. Bull. Am. Meteorol. Soc. 1996, 77, 853-868. [CrossRef]

8. Kopia, L.P. Earth Radiation Budget Experiment Scanner Instrument. Rev. Geophys. 1986, 24, 400-406. [CrossRef] 
9. Luther, M.R.; Cooper, J.E.; Taylor, G.R. The Earth Radiation Budget Experiment Nonscanner Instrument (Paper 5R0789). Rev. Geophys. 1986, 24, 391-399. [CrossRef]

10. Wielicki, B.A.; Barkstrom, B.R.; Baum, B.A.; Charlock, T.P.; Green, R.N.; Kratz, D.P.; Lee, R.B.; Minnis, P.; Smith, G.L.; Takmeng, W.; et al. Clouds and the Earth's Radiant Energy System (CERES): Algorithm overview. IEEE Trans. Geosci. Remote Sens. 1998, 36, 1127-1141. [CrossRef]

11. Rottman, G.; Woods, T.; George, V. The Solar Radiation and Climate Experiment (SORCE). Sol. Phys. 2005, 230, 360-417.

12. Smith, G.L.; Wong, T.; Bush, K.A. Time-Sampling Errors of Earth Radiation From Satellites: Theory for Outgoing Longwave Radiation. IEEE Trans. Geosci. Remote Sens. 2015, 53, 1656-1665. [CrossRef]

13. Smith, G.L.; Wong, T. Time-Sampling Errors of Earth Radiation From Satellites: Theory for Monthly Mean Albedo. IEEE Trans. Geosci. Remote Sens. 2016, 54, 3107-3115. [CrossRef]

14. Harries, J.E.; Russell, J.E.; Hanafin, J.A.; Brindley, H.; Futyan, J.; Rufus, J.; Kellock, S.; Matthews, G.; Wrigley, R.; Last, A.; et al. The Geostationary Earth Radiation Budget Project. Bull. Am. Meteorol. Soc. 2005, 86, 945-960. [CrossRef]

15. De Paepe, B.; Ignatov, A.; Dewitte, S.; Ipe, A. Aerosol retrieval over ocean from SEVIRI for the use in GERB Earth's radiation budget analyses. Remote Sens. Environ. 2008, 112, 2455-2468. [CrossRef]

16. Burt, J.; Smith, B. Deep Space Climate Observatory: The DSCOVR mission. In Proceedings of the Aerospace Conference, Big Sky, MT, USA, 3-10 March 2012.

17. Church, J.A.; White, N.J.; Konikow, L.F.; Domingues, C.M.; Cogley, J.G.; Rignot, E.; Gregory, J.M.; van den Broeke, M.R.; Monaghan, A.J.; Velicogna, I. Revisiting the Earth's sea-level and energy budgets from 1961 to 2008. Geophys. Res. Lett. 2011, 38. [CrossRef]

18. Trenberth, K.E.; Fasullo, J.T.; Balmaseda, M.A. Earth's Energy Imbalance. J. Clim. 2014, 27, 3129-3144. [CrossRef]

19. Abraham, J.P.; Baringer, M.; Bindoff, N.L.; Boyer, T.; Cheng, L.J.; Church, J.A.; Conroy, J.L.; Domingues, C.M.; Fasullo, J.T.; Gilson, J.; et al. A review of global ocean temperature observations: Implications for ocean heat content estimates and climate change. Rev. Geophys. 2013, 51, 450-483. [CrossRef]

20. von Schuckmann, K.; Sallée, J.-B.; Chambers, D.; Le Traon, P.-Y.; Cabanes, C.; Gaillard, F.; Speich, S.; Hamon, M. Monitoring ocean heat content from the current generation of global ocean observing systems. Ocean Sci. Discuss. 2013, 10, 923-949.

21. Desbruyères, D.G.; McDonagh, E.L.; King, B.A.; Garry, F.K.; Blaker, A.T.; Moat, B.I.; Mercier, H. Full-depth temperaturetrends in the northeastern Atlantic through the early 21st century. Geophys. Res. Lett. 2014, 41, 7971-7979. [CrossRef]

22. Goode, P.R.; Qiu, J.; Yurchyshyn, V.; Hickey, J.; Chu, M.-C.; Kolbe, E.; Brown, C.T.; Koonin, S.E. Earthshine observations of the Earth's reflectance. Geophys. Res. Lett. 2001, 28, 1671-1674. [CrossRef]

23. Pallé, E.; Goode, P.R.; Yurchyshyn, V.; Qiu, J.; Hickey, J.; Montañés Rodriguez, P.; Chu, M.-C.; Kolbe, E.; Brown, C.T.; Koonin, S.E. Earthshine and the Earth's albedo: 2. Observations and simulations over 3 years. J. Geophys. Res. Atmos. 2003, 108. [CrossRef]

24. Qiu, J.; Goode, P.R.; Pallé, E.; Yurchyshyn, V.; Hickey, J.; Montañés Rodriguez, P.; Chu, M.-C.; Kolbe, E.; Brown, C.T.; Koonin, S.E. Earthshine and the Earth's albedo: 1. Earthshine observations and measurements of the lunar phase function for accurate measurements of the Earth's Bond albedo. J. Geophys. Res. Atmos. 2003, 108. [CrossRef]

25. Guo, H.; Liu, G.; Ding, Y. Moon-based Earth observation: Scientific concept and potential applications. Int. J. Digit. Earth 2018, 11, 546-557. [CrossRef]

26. Ding, Y.; Guo, H.; Guang, L. Method to estimate the Doppler parameters of moon-borne SAR using JPL ephemeris. Beijing Hangkong Hangtian Daxue Xuebao/J. Beijing Univ. Aeronaut. Astronaut. 2015, 41, 71-76. [CrossRef]

27. Ding, Y.; Guo, H.; Liu, G.; Han, C.; Lv, M. Constructing a High-Accuracy Geometric Model for Moon-Based Earth Observation Remote Sens. 2019, 11, 2611. [CrossRef]

28. Pallé, E.; Goode, P.R. The Lunar Terrestrial Observatory: Observing the Earth using photometers on the Moon's surface. Adv. Space Res. 2009, 43, 1083-1089. [CrossRef]

29. Ren, Y.; Guo, H.; Liu, G.; Ye, H. Simulation Study of Geometric Characteristics and Coverage for Moon-Based Earth Observation in the Electro-Optical Region. IEEE J. Sel. Top. Appl. Earth Obs. Remote Sens. 2017, 10, 2431-2440. [CrossRef]

30. Li, T.; Guo, H.; Zhang, L.; Nie, C.; Liao, J.; Liu, G. Simulation of Moon-based Earth observation optical image processing methods for global change study. Front. Earth Sci. 2019, 14, 236-250. [CrossRef]

31. Sui, Y.; Guo, H.; Liu, G.; Ren, Y. Analysis of Long-Term Moon-Based Observation Characteristics for Arctic and Antarctic. Remote Sens. 2019, 11, 2805. [CrossRef]

32. Ye, H.; Guo, H.; Liu, G.; Ren, Y. Observation scope and spatial coverage analysis for earth observation from a Moon-based platform. Int. J. Remote Sens. 2018, 39, 5809-5833. [CrossRef]

33. Loeb, N.G.; Kato, S.; Wielicki, B.A. Defining Top-of-Atmosphere Flux Reference Level for Earth Radiation Budget Studies. J. Clim. 2002, 15, 3301-3309. [CrossRef]

34. Angular Distribution Models (ADMs). Available online: https://ceres.larc.nasa.gov/data/angular-distribution-models (accessed on 31 August 2021).

35. Loeb, N.G.; Kato, S.; Loukachine, K.; Manalo-Smith, N. Angular Distribution Models for Top-of-Atmosphere Radiative Flux Estimation from the Clouds and the Earth's Radiant Energy System Instrument on the Terra Satellite. Part I: Methodology. J. Atmos. Ocean. Technol. 2005, 22, 338-351. [CrossRef]

36. Su, W.; Corbett, J.; Eitzen, Z.; Liang, L. Next-generation angular distribution models for top-of-atmosphere radiative flux calculation from CERES instruments: Methodology. Atmos. Meas. Tech. 2015, 7, 8817-8880. [CrossRef] 
37. Ligas, M.; Banasik, P. Conversion between Cartesian and geodetic coordinates on a rotational ellipsoid by solving a system of nonlinear equations. Geod. Cartogr. 2011, 60, 145-159. [CrossRef]

38. Earth Coordinate System. Available online: http://abyss.uoregon.edu/ \{\}js/ast121/lectures/lec03.html (accessed on 10 May 2021).

39. Suttles, J.T.; Green, R.N.; Minnis, P.; Smith, G.L.; Staylor, W.F.; Wielicki, B.; Walker, I.J.; Young, D.F.; Taylor, V.R.; Stowe, L.L. Angular Radiation Models for Earth-Atmosphere System. Volume 1: Shortwave Radiation; NASA RP-1184; 1988; pp. 147p.

40. Suttles, J.T.; Wielicki, B.A.; Vemury, S. Top-of-Atmosphere Radiative Fluxes: Validation of ERBE Scanner Inversion Algorithm Using Nimbus-7 ERB Data. J. Appl. Meteorol. 1992, 31, 784-796. [CrossRef]

41. Karlsson, J.; Svensson, G. Consequences of poor representation of Arctic sea-ice albedo and cloud-radiation interactions in the CMIP5 model ensemble. Geophys. Res. Lett. 2013, 40, 4374-4379. [CrossRef]

42. Sohn, B.J.; Nakajima, T.; Satoh, M.; Jang, H.S. Impact of different definitions of clear-sky flux on the determination of longwave cloud radiative forcing: NICAM simulation results. Atmos. Chem. Phys. 2010, 10, 11641-11646. [CrossRef]

43. Shang, H.; Ding, Y.; Guo, H.; Liu, G.; Liu, X.; Wu, J.; Liang, L.; Jiang, H.; Chen, G. Simulation of Earth's Outward Radiative Flux and Its Radiance in Moon-Based View. Remote Sens. 2021, 13, 2535. [CrossRef]

44. Sulla-Menashe, D.; Friedl, M.A. User Guide to Collection 6 MODIS Land Cover (MCD12Q1 and MCD12C1) Product; USGS: Reston, VA, USA, 2018; p. 18.

45. Loeb, N.G.; Kato, S.; Loukachine, K.; Manalosmith, N.; Doelling, D.R. Angular Distribution Models for Top-of-Atmosphere Radiative Flux Estimation from the Clouds and the Earth's Radiant Energy System Instrument on the Terra Satellite. Part II: Validation. J. Atmos. Ocean. Technol. 2005, 24, 564-584. [CrossRef]

46. Smith, G.L.; Priestley, K.J.; Loeb, N.G.; Wielicki, B.A.; Charlock, T.P.; Minnis, P.; Doelling, D.R.; Rutan, D.A. Clouds and Earth Radiant Energy System (CERES), a review: Past, present and future. Adv. Space Res. 2011, 48, 254-263. [CrossRef]

47. CERES_SYN1deg_ED4A Data Quality Summary. 2017. Available online: https://ceres.larc.nasa.gov/documents/DQ summaries/CERES_SYN1deg_Ed4A_DQS.pdf (accessed on 4 August 2021).

48. Petit, G.; Luzum, B. IERS Conventions (2010). IERS Tech. Note 2010, 36.

49. Civicioglu, P. Transforming geocentric cartesian coordinates to geodetic coordinates by using differential search algorithm. Comput. Geoences 2012, 46, 229-247. [CrossRef]

50. Roy, A.E.; Clarke, D. Astronomy: Principles and practice. Bristol Hilger 2003, 77, 342-343. 